\title{
Biotechnological production and application of the antibiotic pimaricin: biosynthesis and its regulation
}

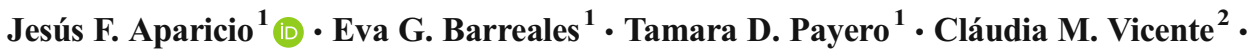 \\ Antonio de Pedro $^{1} \cdot$ Javier Santos-Aberturas ${ }^{3}$
}

Received: 1 September 2015 / Revised: 6 October 2015 / Accepted: 11 October 2015 / Published online: 29 October 2015

(C) The Author(s) 2015. This article is published with open access at Springerlink.com

\begin{abstract}
Pimaricin (natamycin) is a small polyene macrolide antibiotic used worldwide. This efficient antimycotic and antiprotozoal agent, produced by several soil bacterial species of the genus Streptomyces, has found application in human therapy, in the food and beverage industries and as pesticide. It displays a broad spectrum of activity, targeting ergosterol but bearing a particular mode of action different to other polyene macrolides. The biosynthesis of this only antifungal agent with a GRAS status has been thoroughly studied, which has permitted the manipulation of producers to engineer the biosynthetic gene clusters in order to generate several analogues. Regulation of its production has been largely unveiled, constituting a model for other polyenes and setting the leads for optimizing the production of these valuable compounds. This review describes and discusses the molecular genetics, uses, mode of action, analogue generation, regulation and strategies for increasing pimaricin production yields.
\end{abstract}

Keywords Antifungal agent $\cdot$ Cheese $\cdot$ Gene regulation $\cdot$ Keratitis $\cdot$ Metabolic engineering $\cdot$ Polyene macrolide . Preservative E-235 - Streptomyces

Jesús F. Aparicio

jesus.aparicio@unileon.es

1 Area of Microbiology, Faculty of Biology, Universidad de León, 24071 León, Spain

2 Dynamique des Génomes et Adaptation Microbienne, UMR 1128, INRA, Université de Lorraine, 54506 Vandoeuvre-lès-Nancy, France

3 Department of Molecular Microbiology, John Innes Centre, Norwich Research Park, Norwich NR4 7UH, UK

\section{Introduction}

Pimaricin (PIM), also called natamycin, tennecetin, natacyn and E235, is a natural product produced by given members of the genus Streptomyces, a class of filamentous soil-dwelling bacteria that undergo a complex life cycle involving differentiation and sporulation. It belongs to the polyene class of macrolide polyketides, and displays a strong and broad spectrum mould inhibition activity, yet being safe and effective at very low concentrations. Because its molecular target is ergosterol, an essential constituent of fungal membranes, and bacteria do not contain sterols in their membranes, it is inactive against bacteria. For the same reason, it is extremely reluctant to microbial resistance since the only way fungi would have to evade its action would be to change sterols from their membranes. For these reasons, and because of its low toxicity to mammalian cells, this molecule has become one of the major mould inhibitors used in the food industry. Its use was approved in 1967 as a cheese preservative, and since then, it has been extended to a wide variety of foods and beverages. In addition, PIM has been regarded as the most important agent in the management of fungal keratitis, a leading cause of blindness in corneal diseases, which is relatively common in warm climates and developing countries. Furthermore, it is also used as a crop protection agent to prevent mould contamination. Besides its antifungal action, it is also active against protozoa having ergosterol in their membranes.

Useful reviews about polyene macrolide biosynthesis and analogue generation are available in the literature (Aparicio et al. 2003; Aparicio et al. 2004; Caffrey et al. 2008; Kong et al. 2013). This mini-review provides a general view of the applicability of PIM, describes its particular mode of action and highlights the recent advances in the molecular genetics and metabolic engineering of its biosynthetic pathway to produce PIM derivatives with enhanced properties. It also 
provides important insights about the considerable progress attained in recent years aimed to unveil the complex network of regulators involved in its biosynthesis and discusses different strategies for increasing production yields.

\section{Discovery and structure}

PIM is a small-sized polyene antibiotic. Its name derives from the South African region of Natal ('Christmas' in Portuguese, Vasco da Gama having landed on its shores on 25 December 1497), where the first producing strain, Streptomyces natalensis, was isolated (Struyk et al. 1957-1958). In addition, other strains like $S$. gilvosporeus, S. lydicus and S. chatanoogensis have also been identified as PIM producers.

Its structural core is a 26-membered macrolactone ring with four conjugated double bonds (chromophore) (Fig. 1). Its tetraene nature was unveiled shortly after its discovery (Patrick et al. 1958), but its correct covalent structure was not solved until 1966 (Golding et al. 1966) and its stereochemical structure some 24 years later (Lancelin and Beau 1990). More recently, its solution NMR structure has been described (Volpon and Lancelin 2002). Like most glycosylated polyenes, its molecule contains a mycosamine (3-amino-3,6dideoxy-D-mannose) moiety linked to the macrolactone ring via a $\beta$-glycosidic bond at $\mathrm{C} 15$. In the aglycone, the most characteristic features are the presence of an epoxide group at $\mathrm{C} 4-\mathrm{C} 5$, which originates from a double bond (Mendes et al. 2001, 2005); an exocyclic carboxyl function at C12 that derives from a methyl group (Caffrey et al. 2008; Martín and
Aparicio 2009; Qi et al. 2015; Liu et al. 2015b); and an internal hemiketal ring resulting from spontaneous cyclisation between a keto group at $\mathrm{C} 9$ and a hydroxyl group at $\mathrm{C} 13$ (Aparicio et al. 2000) (Fig. 1). Because of the presence of the chromophore in its structure, PIM shows characteristic physicochemical properties, including a strong UV-visible light absorption and photolability. The UV-visible light absorption spectrum of PIM shows a characteristic shape due to its multipeak pattern (Fig. 1). Like in all polyenes, the chromophore is located opposite to a number of hydroxyl functions, making PIM strongly amphipathic, the region where the chromophore lies has a planar and rigid lipophilic nature, whilst the hydroxylated region is typically flexible and hydrophilic (Bolard 1986). This feature allows the molecule to interact with the sterol molecules present in fungal cell membranes (predominantly ergosterol), by means of hydrophobic interactions between the hydrophobic portion of the polyene and the sterol, which results in cell death (Aparicio et al. 2004).

Because of its amphiphilic nature, it is poorly soluble in water and almost insoluble in non-polar solvents. As a powder, it is stable in the dark, with no loss of activity, but it is light sensitive in aqueous suspensions. Its CAS number is 7681-93-8.

\section{Bioactivity}

PIM has a strong antifungal activity on most fungi (minimal inhibitory concentrations are in the micromolar range). For many years, it was thought that its mode of action on
Fig. 1 Structures of PIM and its target ergosterol. The UV-visible absorption spectrum of PIM is also included

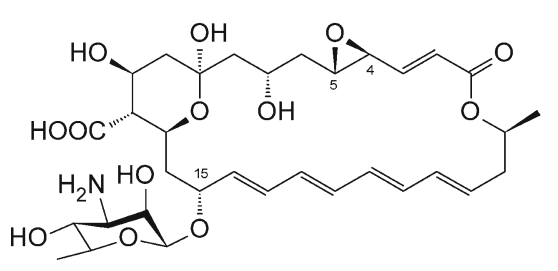

Pimaricin

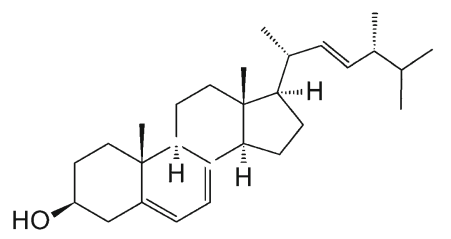

Ergosterol

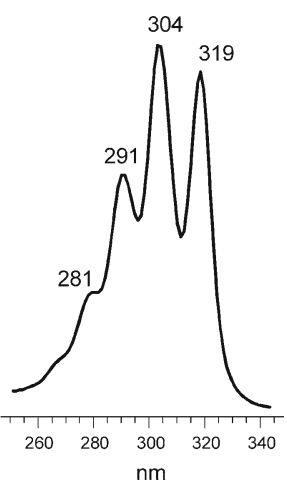

$\mathrm{nm}$ 
fungal membranes was to act as a permeabilising agent, as occurs with other polyenes (Bolard 1986). However, in clear contrast to large glycosylated polyenes like nystatin or amphotericin B that kill fungi by forming ion-permeable pores upon binding to ergosterol (Fujii et al. 1997; Baginski et al. 1997, 2006), or to the small polyene filipin which lacks the mycosamine moiety and also the carboxyl group, and is thought to interact with sterols by forming a sandwich-like structure embedded within the hydrophobic core of the lipid bilayer, which results in membrane fragmentation and cellular leakage (de Kruijff and Demel 1974; Knopik-Skrocka and Bielawski 2002), PIM blocks fungal growth by binding specifically to ergosterol but without permeabilising the membrane (te Welscher et al. 2008).

Thus, unlike other polyene antibiotics, PIM does not seem to form membrane disruption complexes and its action must be correlated with the alteration of the normal functioning of ergosterol in the fungal membrane. Ergosterol is the principal sterol in fungal cells, and has been correlated with multiple functions, including endocytosis, exocytosis, vacuole fusion, polarity and morphogenesis (Munn 2001; Kato and Wickner 2001; Heese-Peck et al. 2002; Martin and Konopka 2004; Wachtler and Balasubramanian 2006; Mysyakina and Funtikova 2007; Takeshita et al. 2008; Jin et al. 2008). Recently, Van Leeuwen et al. (2009) have proven that PIM inhibits endocytosis in germinating conidia of Penicillium discolor without causing extensive cell damage (i.e. without membrane permeabilisation), and Breukink and his group have also found that PIM impairs vacuole fusion via perturbation of ergosterol-dependent priming reactions that precede membrane fusion (te Welscher et al. 2010). Given that the priming phase consists solely on protein rearrangements, they pointed out to a more general mode of action such as the disturbance of ergosteroldependent protein functions (te Welscher et al. 2010). This hypothesis was demonstrated only 2 years later, when they proved that PIM inhibits growth of yeasts and fungi via the immediate inhibition of amino acid and glucose transport across the plasma membrane by an ergosterol-dependent inhibition of transport proteins (te Welscher et al. 2012).

Because its molecular target is ergosterol, a structural constituent of fungal membranes, PIM, is extremely unlikely to provoke microbial resistance (Aparicio et al. 2004).

Besides its antifungal action, PIM has been involved in the immune response activation by triggering interleukin$1 \beta$ secretion through activation of the NLRP3 inflammasome (Darisipudi et al. 2011). The mechanism of activation relies on the induction of potassium efflux from the cells as well as on phagocytosis-dependent lysosome destabilisation. This suggests that besides inhibiting fungal growth directly, it may also suppress fungal growth indirectly via activating innate host defence.
Additionally, this polyene has also been found to be active 'in vitro' against several protozoa such as Trypanosoma (Rolón et al. 2006) or Acanthamoeba (Sunada et al. 2014). These organisms have ergosterol-derived compounds as components of their membranes, making PIM or its derivatives also potentially useful as antiparasitic agents.

\section{Applications}

\section{Therapy}

PIM has found clinical application as a topical agent in the treatment of various fungal infections, including oral, intestinal or vulvovaginal candidiasis (Cevher et al. 2008). But the most important playground for PIM is in the treatment of ophthalmic mycoses. PIM was the first antifungal agent approved by the Food and Drug Administration (FDA) of the United States (in 1978); it can be used for the treatment of fungal blepharitis, conjunctivitis, scleritis and endophthalmitis (Thomas 2003) and constitutes the first-line treatment in fungal keratitis (Ansari et al. 2013). It possesses activity against a great variety of yeast and filamentous fungal pathogens, including Alternaria, Candida, Cephalosporium, Colletotrichum, Curvularia, Lasiodiplodia, Scedosporium, Trichophyton and Penicillium spp. (Kaliamurthy et al. 2004; Thomas and Kaliamurthy 2013; Hsiao et al. 2014), and is currently considered the most effective medication against Fusarium and Aspergillus (Lalitha et al. 2007). Additionally, PIM is also effective for the treatment of keratitis produced by protozoa such as Acanthamoeba (Sunada et al. 2014).

\section{Food}

Because of its broad spectrum of activity, its low likelihood of causing microbial resistance and especially its low toxicity to mammalian cells (Arima et al. 2014), PIM has been widely used as a food preservative for more than 40 years (Fig. 2). It is significantly more effective than sorbate, another commonly used antifungal preservative (Shibata et al. 1991; Pipek et al. 2010). When applied on the surface of foods, it does not affect its organoleptic properties (taste, texture and colour), and has prolonged antimicrobial activity, being safe for consumption because its oral absorption is negligible (Juneja et al. 2012). It has been authorised by the European Food Safety Authority (EFSA) (additive E235), the World Health Organisation (WHO) and the FDA for protecting foods from yeast and mould contamination and possible inherent risks of mycotoxin poisoning. Notably, it is the only antifungal agent with a generally regarded as safe (GRAS) status.

Since bacterial membranes are devoid of sterols, PIM is not active against bacteria, thus making it an ideal antimicrobial during bacterial ripening and fermentation processes for fermented foods. Thus, it has been traditionally used as a 


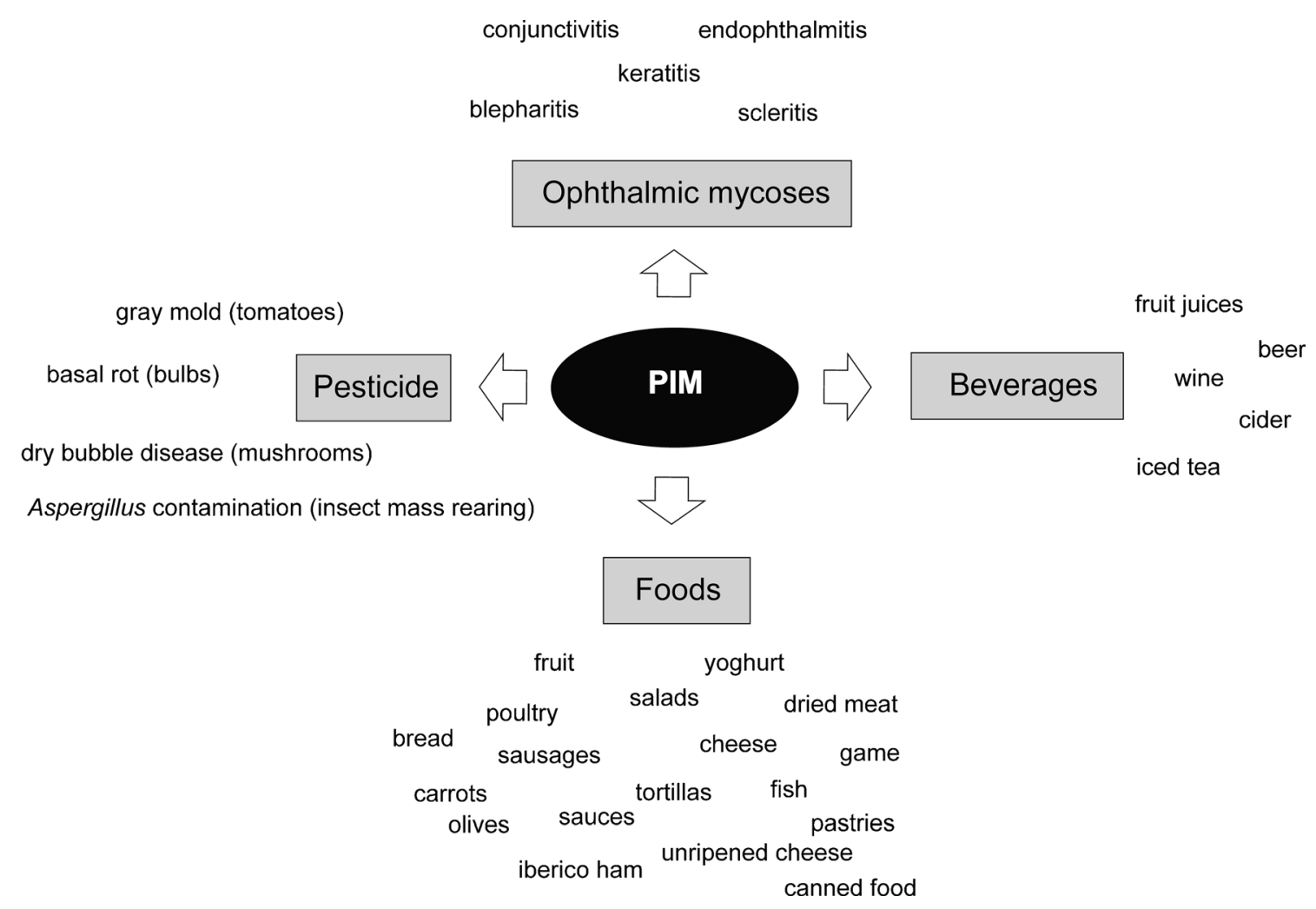

Fig. 2 Applications of PIM

preservative in cheese and cured sausage production (Stark 2003). It is used for the surface treatment of almost every type of cheese, either added as an emulsion for coating the cheese rind or applied by dipping or spraying. Under these conditions, PIM crystals remain on the surface of the product, and the soluble fraction hardly penetrates (Stark 2003), thus not interfering with the internal microorganisms that confer their organoleptic properties to these products. Sausages are treated with PIM by dipping or spraying to prevent fungal growth during ageing.

Besides its major application on cheese and sausages, PIM can also be used to prevent mould growth in yoghurt and other dairy products such as unripened cheese (e.g. cream cheese, cottage cheese and mozzarella) or whey protein cheese (e.g. ricotta), also in dried uncooked meats and in iberico and prosciutto hams. PIM can also be used to extend the shelf life of different fruit and vegetable preparations, salad mixes, baking products, sauces, fish, poultry, etc. (Fig. 2). Recently, PIM has been used to successfully inhibit the growth of fungi during natural black olive fermentation (Hondrodimou et al. 2011) and to prevent carrot spoilage in refrigerated storage facilities (de Vries et al. 2008).

Besides its direct application on foods, PIM has been successfully incorporated into different packaging films/coatings (de Oliveira et al. 2007; Pintado et al. 2010; Hanusová et al. 2010; Jiang et al. 2013b), including some that are edible (Fajardo et al. 2010), where it has proven to be gradually released over long periods of time, thus extending the shelf life of the product. This 'active packaging' is receiving great attention, since in several countries, there are restrictions on the direct use of PIM with certain foods.

\section{Beverages}

PIM has also been described to be very effective for controlling growth of Aspergillus carbonarius, the fungus responsible for contamination of wine, grapes and grape juice with ochratoxin A (one of the most abundant mycotoxins) (Medina et al. 2007). PIM is used to prevent fungal spoilage in other beverage products before their packaging, as it is effective at low concentrations, it is stable if kept protected from light and it is not affected by a wide range of $\mathrm{pH}$ values (Juneja et al. 2012). Regulations vary from one country to another but depending on the country; it may be used in fruit juices, beer, wine, cider or iced tea (Mann and Beuchat 2008; Siricururatana et al. 2013) (Fig. 2).

\section{Pesticide}

Furthermore, PIM is also used as a natural and safe product for crop protection. It is used to control various fungal diseases but especially basal rots on ornamental bulbs such as daffodils that are caused by Fusarium oxysporum (Copping and Duke 2007). Its efficacy to control tomato gray mould disease 
caused by Botrytis cinerea in greenhouse conditions has also been reported (Lu et al. 2008). In 2012, it has been approved as a biopesticide by the US Environmental Protection Agency for its use in enclosed mushroom production facilities to prevent dry bubble disease caused by Lecanicillium fungicola, a devastating pathogen in the mushroom industry. Recently, its efficacy controlling Aspergillus niger contamination in rice leaffolder larvae (Cnaphalocrocis medinalis, a Lepidoptera important for rice growth) mass-rearing facilities has been reported (Su et al. 2014).

Other applications include its use in selective growth media to prevent growth of yeast and filamentous fungi, such as in the isolation of Brucella (Stack et al. 2002) or Legionella spp. (Edelstein and Edelstein 1996).

\section{Biosynthesis and export}

PIM, like other macrocyclic polyketides, is synthesised by the action of so-called type I modular polyketide synthases (PKSs) (Aparicio et al. 2003) that sequentially assemble carbon chains from small acyl precursors, in a fashion that mechanistically resembles fatty acid biosynthesis. But, whereas in fatty acid biosynthesis, each elongation step is followed by a complete set of reactions including ketoreduction, dehydration and enoylreduction; in the synthesis of PIM and other macrolides, the product of each decarboxylating condensation may undergo all, some or none of the abovementioned modifications, thus resulting in alkanes, double bonds, hydroxyl groups or ketones at defined positions of the polyketide chain. Finally, a thioesterase domain located at the C-terminal end of the last PKS (PimS4) releases the chain by lactonisation. Once the first macrolide intermediate is formed (pimaricinolide), it becomes the substrate of three functionalisation enzymes that carry out specific oxidations and a glycosylation to yield the final PIM molecule (see below).

Biosynthetic genes from $S$. natalensis were the first described for a polyene macrolide (Aparicio et al. 1999), and since then, the whole cluster responsible for the biosynthesis of PIM (pim) from 12 acetate and one propionate units has been thoroughly studied (Martín and Aparicio 2009) (Table 1). The cluster from another PIM producer such as $S$. chattanoogensis has been described later and named scn (Du et al. 2011a). The cluster from S. natalensis is divided into two subclusters which encode a highly complex PKS distributed in five multifunctional polypeptides (PimS0 to PimS4) harbouring 13 homologous sets of enzyme activities (modules) and a total of 60 catalytic domains (Aparicio et al. 2000). The DNA region contains 15 additional open reading frames which govern post-PKS modification of the polyketide skeleton, export and regulation of gene expression (Table 1).

Both clusters show a large degree of synteny. Compared with the scn cluster, the pim cluster contains only two major strain-specific differences, which correspond to $\operatorname{pim} H$, an efflux pump-encoding gene (Aparicio et al. 2000), and pimT that encodes an amino acid exporter (Vicente et al. 2009) involved in modulating PIM production via secretion of the PIM inducer 2,3-diamino-2,3-bis(hydroxymethyl)-1,4-butanediol (PI factor) (Recio et al. 2004). Both genes are located at the two ends of the cluster (Table 1). In turn, the scn cluster contains a putative transposase gene located downstream from scnS1, the PKS in charge of the first elongation step in polyketide construction. Interestingly, although the coding regions of the two clusters are highly conserved, the intergenic regions are much more variable, thus accounting for a different transcriptional organisation between them (Du et al. 2011a) (Table 1).

The construction of PIM macrolide skeleton is initiated by PimS0 and ends at PimS4 that thanks to its terminal thioesterase domain releases the growing chain from the enzyme and cyclises it to yield a 26-membered macrocyclic lactone (pimaricinolide) (Fig. 3). The fidelity of chain construction has been demonstrated to be dependent on scnI (the pimI orthologue from $S$. chattanoogensis). This discrete thioesterase plays an important editing role in the selection of starter acyl units and in the removal of aberrant extender units during PIM biosynthesis (Wang et al. 2014a). It can be complemented by other discrete thioesterases (Wang et al. 2014a), and it is conceivable that it could also have a complementary role with the terminal thioesterase domain of PimS4. Once the aglycone is synthesised, a cytochrome P450 enzyme, $\operatorname{pim} G$, was proposed to catalyse an oxidation of the exocyclic methyl group at $\mathrm{C} 12$ via triple hydroxylations, to form a carboxyl group, yielding 12-carboxypimaricinolide (Martín and Aparicio 2009). This hypothesis has recently been proven by inactivation of pim $G$ orthologue scn $G$ form $S$. chattanoogensis L10 (Liu et al. 2015b). Then, the amino sugar mycosamine is attached to the macrocyclic aglycone at C15 by the glycosyltransferase pimK to yield 4,5deepoxypimaricin (Fig. 3) (Mendes et al. 2005; Liu et al. 2015b), and finally, another P450 monooxygenase, pimD, catalyses the last oxidation step to yield an epoxy group between C4 and C5 from a double bond generated by the PKS (Mendes et al. 2001, 2005). The X-ray structure of this latter P450 has been resolved, both substrate-free and in complex with 4,5deepoxypimaricin (Kells et al. 2010).

The mycosamine sugar is synthesised from guanosine diphosphate (GDP)-mannose derived from fructose-6-phosphate (Nic Lochlainn and Caffrey 2009). Inactivation of pimJ orthologue amphDIII in the amphotericin-producing strain $S$. nodosus resulted in accumulation of amphoteronolides demonstrating that mycosamine is biosynthesised from GDPmannose (Byrne et al. 2003), and heterologous expression of the orthologue from nystatin biosynthesis nysDIII has proven that the first step in the mycosamine-specific pathway is carried out by GDP-mannose 4,6-dehydratase (Nedal et al. 2007) (Fig. 3). Thus, pimJ is proposed to catalyse conversion of GDP-mannose to GDP-4-keto-6-deoxymannose, which 
Table 1 Comparison of PIM clusters and transcriptional units from S. natalensis and S. chattanoogensis

\section{S. natalensis}

Gene
pimT
pimM
pimR
pimS4
pimS3
pimS2
pimI
pimJ
pimA
pimB
pimE
pim $\mathrm{Pim}$

A

pimS1

Function

PIM inducer PI factor secretion

PAS-LuxR regulator

SARP-LAL regulator

Mycosamine transferase

PKS Extension module 12, cyclisation and chain release

PKS Extension module 11

PKS Extension modules 5-10

Thioesterase (type II)

GDP-mannose 4,6-dehydratase

$\mathrm{ABC}$ transporter (PIM export)

$\mathrm{ABC}$ transporter (PIM export)

Cholesterol oxidase

GDP-3-keto-6-deoxymannose aminotransferase

P450 monooxygenase (C12 hydroxylase)

Ferredoxin

PKS Loading module

Tyrosine phosphatase

Transposase

PKS Extension modules 1-4

P450 monooxygenase ( $\mathrm{C} 4,5$ epoxidase)

PIM efflux pump

\section{S. chattanoogensis}

Gene

A

scnRII

scnRI

$\operatorname{scnK}$

$\operatorname{scnS4}$

scnS3

scnS2

$s c n I$

scnJ

$\operatorname{scn} A$

$\operatorname{scn} B$

scnE

$\operatorname{scn} C$

$\operatorname{scn} G$

scnF

scnSo

$\operatorname{scn} L$

$\operatorname{tnp}$

scnS1

$\operatorname{scn} D$

A

Arrows indicate the organization of transcriptional units. $\mathrm{A}=$ absent

presumably undergoes a spontaneous 3,4-isomerisation to give GDP-3-keto-6-deoxymannose (Aparicio et al. 2003), the substrate of the aminotransferase pimC for biosynthesis of GDP-3- amino-3,6-dideoxymannose (GDP-mycosamine). Finally, the glycosyltransferase $\operatorname{pim} K$ catalyses the attachment of mycosamine to the pimaricinolide (Mendes et al. 2005). 

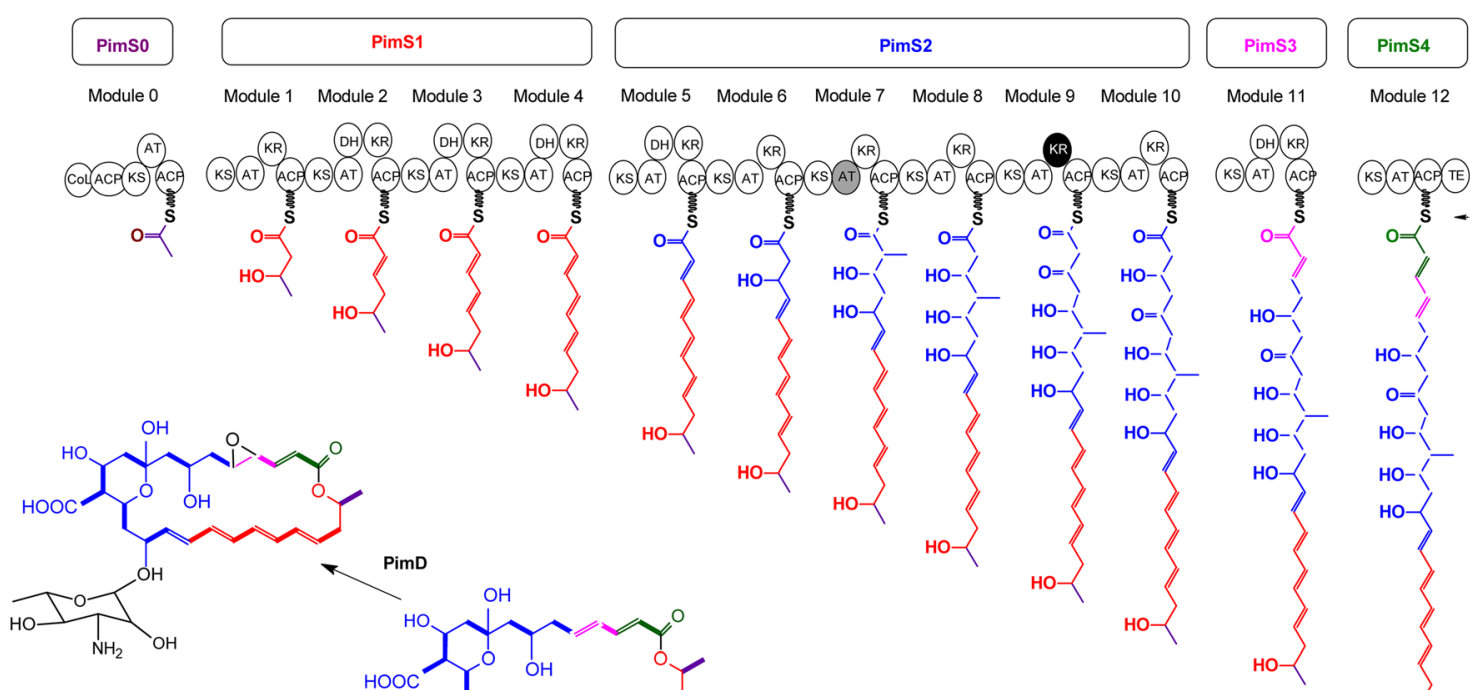

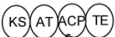

s.

,
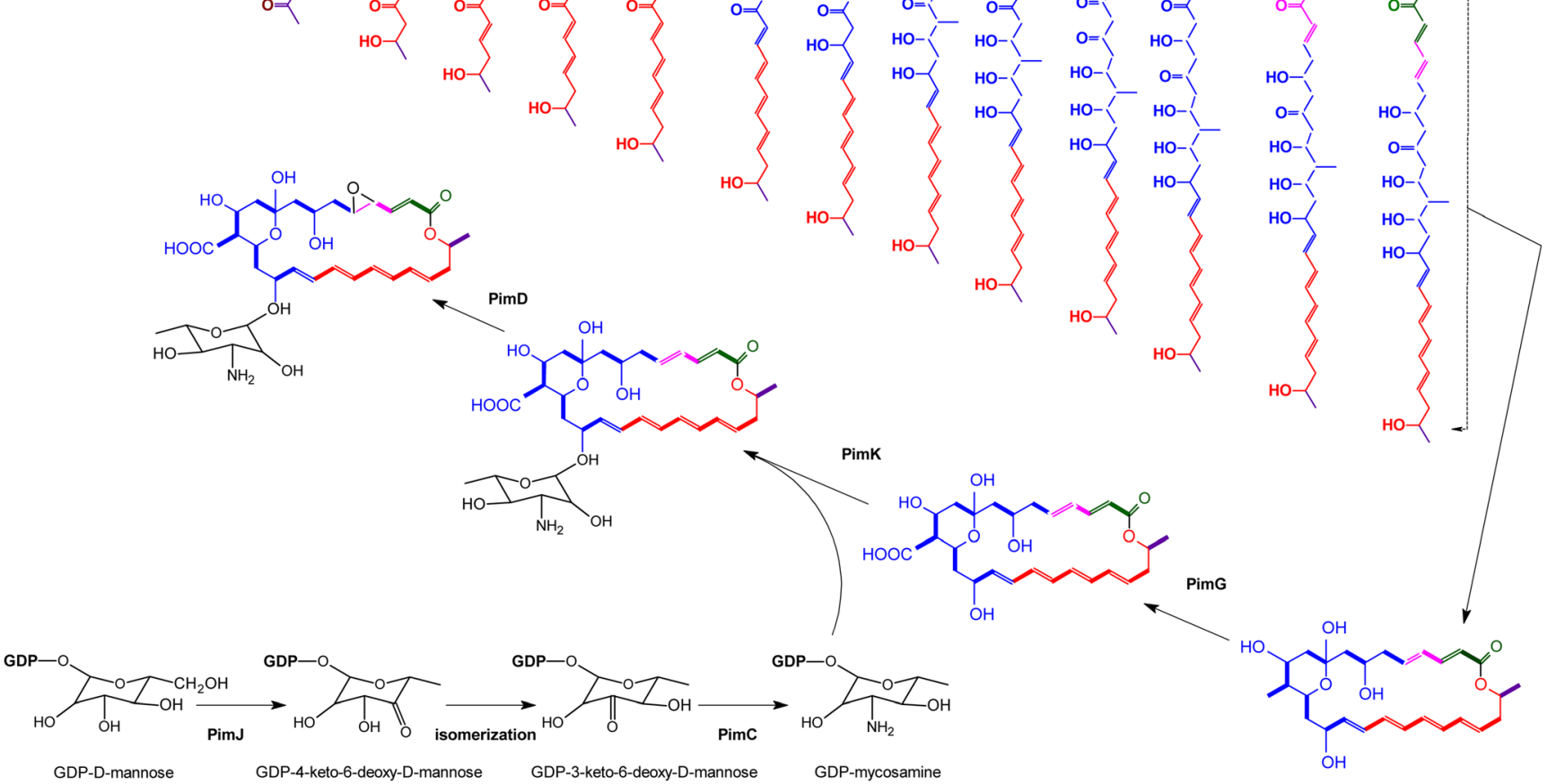

thioesterase. The KR domain in black (module 9) is predicted to be inactive. The AT in module 7 (grey) is predicted to incorporate a propionate extender unit. Biosynthetic pathway for mycosamine is also included. The isomerisation step is thought to be spontaneous

domain. $A C P$ acyl carrier protein, $A T$ acyltransferase, $C o L$ carboxylic acid:CoA ligase, $D H$ ß-hydroxyacyl-thioester dehydratase, $K R ß$ ketoacyl-ACP reductase, $K S$ B-ketoacyl-ACP synthase, and $T E$

Due to its mode of action, PIM does not have any antibacterial activity and thus should not represent a threat to the producing organism; however, its accumulation inside the cell may be harmful, which suggests that producing organisms should ensure an active efflux. The products of three genes in the cluster might be involved in PIM export in S. natalensis. Two of them belong to type III ATP-binding cassette (ABC) transporter proteins, which combine both ATPase and transmembrane domains within the same polypeptide (Mendez and Salas 2001). These, pimA and $\operatorname{pim} B$, are thought to associate forming a heterodimer (Aparicio et al. 2003), and their role in PIM secretion has been deduced upon inactivation of the pimA and $\operatorname{pim} B$ homologues, $n y s H$ and $n y s G$, which encode the nystatin $\mathrm{ABC}$ heterodimer transporter. Such mutants still exported some amount of nystatin, suggesting the existence of alternative transport systems for this antifungal antibiotic (Sletta et al. 2005). Such alternative transport system, in the case of PIM, could be constituted by the putative efflux pump encoded by pimH (Aparicio et al. 2000).

\section{Metabolic engineering and semi-synthetic derivatives}

In the search for improvement of PIM properties, a good number of semi-synthetic derivatives have been described in the literature, including esters (Bonner et al. 1972; Falkowski et al. 1979), N,N-dialkyl (Paquet and Carreira 2006), N-alkyl (Suloff et al. 2003), N-acyl (Nirgudkar et al. 1988), N-glycosil (Falkowski et al. 1980), N-aryl (Belakhov et al. 2010) and hydrophosphoryl derivatives (Belakhov et al. 2008), amongst others. Liposomal preparations have been also studied (Bouaoud et al. 2015).

Moreover, the knowledge of PIM biosynthetic pathway, and the development of an efficient conjugation system for S. natalensis (Enríquez et al. 2006), has allowed the generation, by genetic manipulation, of a number of less toxic or more water-soluble derivatives (Caffrey et al. 2008; Kong et al. 2013).

The first PIM derivative obtained by genetic engineering of S. natalensis was its immediate precursor, 4,5deepoxypimaricin (DEP) (Mendes et al. 2001). This was obtained by disruption of pimD, the gene encoding the cytochrome $\mathrm{P} 450$ monooxygenase responsible for epoxidation at C4-C5 that constitutes the last step of PIM biosynthesis (Mendes et al. 2005; Kells et al. 2010). This compound showed a clear decrease in antifungal activity, thus highlighting the importance of the epoxide group in the interaction of PIM with the fungal membrane. Recently, it has been shown that DEP can be accepted as a substrate by nysL, the pimD homologue 
responsible for the introduction of the last hydroxylation in the biosynthesis of nystatin (Volokhan et al. 2006), thus generating 6-hydroxy-4,5-deepoxypimaricin (6-OH-DEP) (SantosAberturas et al. 2015), which does not show an improvement in antifungal activity compared to DEP. Additionally, it has been shown that both DEP and 6-OH-DEP can undergo carboxamidation reactions catalysed by the amidotransferase PscA, thus resulting in carboxamidated derivatives (4,5-deepoxy-AB-400 and 6-hydroxy-4,5-deepoxy-AB-400, respectively; see Fig. 4) exhibiting improved antifungal activity in comparison with their carboxylated precursors (SantosAberturas et al. 2015). PscA and its homologous protein, $\mathrm{PscB}$, are responsible for the natural occurrence of tetraene carboxamidated compounds (Seco et al. 2005, 2010; Miranzo et al. 2010), including AB-400, the PIM carboxamidated derivative (Cañedo et al. 2000). PscA has shown a much broader substrate that scope PscB, a fact that makes it a stronger candidate for the development of future polyene derivatives (Seco et al. 2010; Santos-Aberturas et al. 2015).

The recent manipulation of the PIM biosynthetic pathway in S. chattanoogensis has led to the production of new PIM derivatives by knocking out $\operatorname{scn} G$, which encodes the P450 monooxygenase (homologous to $\operatorname{pim} G$ ) proposed to be responsible for the formation of the carboxyl exocyclic group (Martín and Aparicio 2009) (Fig. 3). This gene disruption resulted in the accumulation of 4,5-deepoxy-12-decarboxy-12methyl PIM, thus indicating that glycosyltransferase $\operatorname{scnK}$ is able to add the mycosamine moiety to the decarboxylated aglycone whilst $s c n D$ is unable to introduce the epoxide group (Fig. 3) (Liu et al. 2015b). In contrast, the inactivation of the same gene by Qi et al. (2015) resulted in accumulation of 12-decarboxy-12-methyl PIM in addition to that of 4,5deepoxy-12-decarboxy-12-methyl PIM (Fig. 4), thus suggesting that $s c n D$ might be able to introduce the epoxide group to some extent. 12-Decarboxy-12-methyl PIM might be interesting since it shows decreased haemolytic effects together with a twofold increase of the original PIM antifungal activity levels (Qi et al. 2015). These authors have also characterised the bioactivity of 4,5-deepoxy-12-decarboxy-12-methyl PIM, showing that it maintains the PIM antifungal activity whilst exhibiting a decreased haemolytic effect. Interestingly, the mutant obtained by Qi et al. (2015) also accumulated the nonantifungal and non-haemolytic 2-hydro-3-hydroxy-4,5deepoxy-12-decarboxy-12-methyl PIM (Fig. 4), suggesting that the $s c n G$-catalysed carboxylation might occur during the PKS assembly and not after it. In addition, the disruption of
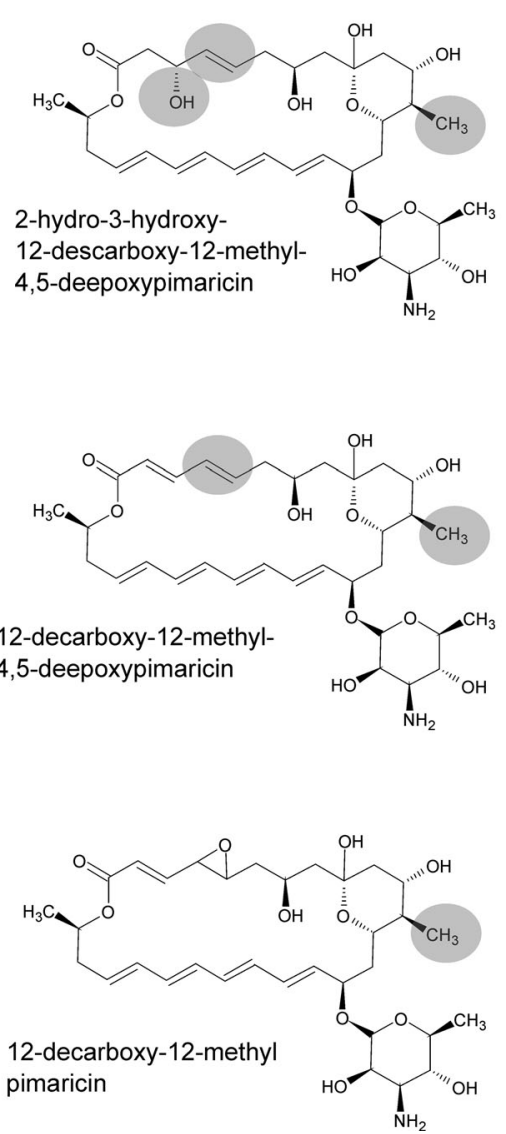
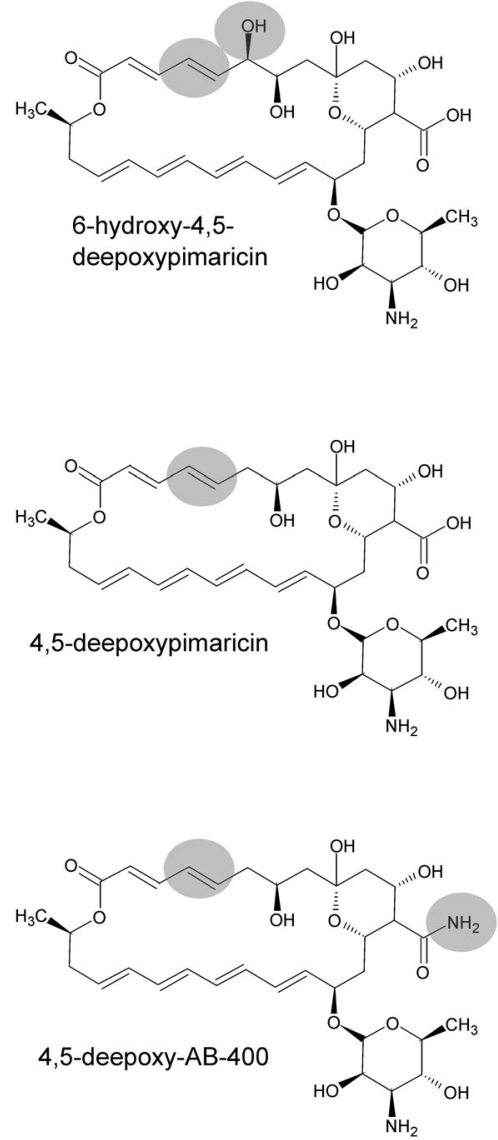
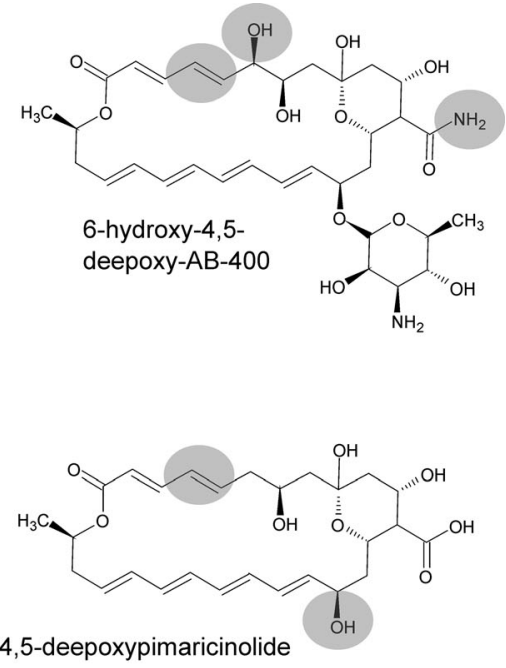

4,5-deepoxypimaricinolide

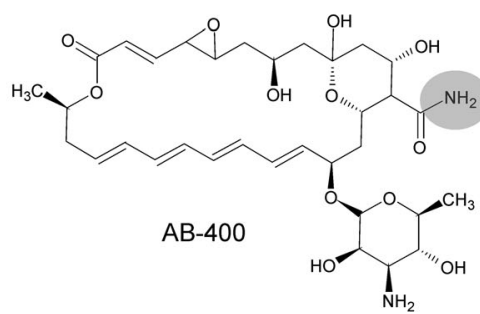

Fig. 4 PIM derivatives obtained by metabolic engineering of the biosynthetic gene cluster. The grey circles highlight structural differences from the original PIM molecule 
scnK in S. chattanoogensis (Liu et al. 2015a, b) led to the accumulation of the 4,5-deepoxypimaricinolide aglycone (Fig. 4), which shows no antifungal activity by itself but could constitute an interesting scaffold for the introduction of alternative sugar moieties by semi-synthetic, mutasynthetic or protein engineering approaches. The accumulation of that intermediate supports the idea that $\operatorname{scn} G(\operatorname{pim} G)$ acts before the glycosylation step in the PIM biosynthetic pathway (Fig. 3).

\section{Regulation}

As occurs with most secondary metabolites synthesised by Streptomyces, PIM production takes place in a growthdependent manner and is governed by complex regulatory networks that respond to population density and a variety of environmental and physiological signals (van Wezel and McDowall 2011; Liu et al. 2013). One of the key players of these networks is transcriptional regulation.

\section{Transcriptional control by cluster-situated regulators}

Transcriptional regulation is a complex process involving multiple signals and an intricate network of regulators that cross talk with each other. Typically, the lowest level is played by so-called pathway-specific transcriptional regulators, which are encoded within the respective biosynthetic gene clusters. Two transcriptional regulators are encoded by the PIM gene cluster, pimR and pimM.

PimR was the first pathway-specific transcriptional regulator of PIM biosynthesis to be described and also the first of its class (Antón et al. 2004). It is a transcriptional activator (knockout mutants fail to produce PIM) with a peculiar architecture. It combines an $\mathrm{N}$-terminal streptomyces antibiotic $\underline{\mathrm{r}}-$ egulatory protein (SARP) DNA-binding domain with a Cterminal half homologous to guanylate cyclases and large ATP-binding regulators of the LuxR family (LAL) (Antón et al. 2004). The C-terminal half includes the ATP/GTPbinding domain characteristic of these protein families but lacks the characteristic signature sequence at the N-terminus of guanylate cyclases or the LuxR-type helix-turn-helix (HTH) motif for DNA-binding present at the C-terminus of LAL regulators (Guerra et al. 2012). Recently, we have characterised pimR mode of action by means of electrophoretic mobility shift assays (EMSAs), DNaseI protection studies, reverse transcription quantitative PCR (RT-qPCR) and gene promoter replacement experiments and determined that it binds a single operator that contains three heptameric direct repeats of the consensus CGGCAAG with 4-bp spacers (Santos-Aberturas et al. 2012). Such operator lies in the promoter region of pimM, whose expression is activated upon pimR binding. Interestingly, the binding sequence of pimR (TGGCAAGAAAGCGGCAGGTGTTCGGCAAG) is exactly conserved in the intergenic region between scnRII and
scnRI in the scn gene cluster of $S$. chattanoogensis (pimM and $\operatorname{pim} R$ counterparts, respectively (Du et al. 2011a)) and also between $p t e F$ and pteR, the corresponding counterparts in the filipin gene cluster of $S$. avermitilis, including the interheptamer nucleotides.

Regulators with a similar architecture include the orthologues pteR and filR involved in filipin biosynthesis in S. avermitilis (Ikeda et al. 2003) and S. filipinensis, respectively (Payero et al. 2015), but also regulators of peptidyl nucleoside antibiotic biosynthesis such as nikkomycins $(\operatorname{san} G)$ and polyoxins (polR) (Liu et al. 2005; Li et al. 2009). Filipin is a pentaene macrolide, whilst nikkomycins and polyoxins are peptidyl nucleoside antibiotics. Interestingly, all these compounds are effective antifungals, and it has been speculated that the domain arrangement of these regulatory proteins might be related with the detection of common signals involved in the triggering of antifungal production (SantosAberturas et al. 2012). Noteworthy, the consensus heptamer for pimR is identical to those of san G (He et al. 2010) and polR (Li et al. 2009), although in these cases, only two heptameric repeats are present in the operator.

PimM was the second transcriptional activator of PIM biosynthesis to be described (PIM production is abolished in deleted mutants) (Antón et al. 2007). It also has a peculiar architecture, combining an N-terminal PAS sensory domain (Hefti et al. 2004) with a C-terminal helix-turn-helix motif of the LuxR type for DNA binding (Santos et al. 2012). The PAS domain detects a physical or chemical stimulus and regulates, in response, the activity of the effector domain (Möglich et al. 2009). Unlike most other sensors, proteins containing PAS domains are located in the cytosol, and therefore, they detect internal signals, but they can also sense environmental factors that cross the cell membrane. In contrast with the majority of prokaryotic PAS domain-containing regulators, which are sensor kinases of two-component systems (Taylor and Zhulin 1999), pimM does not belong to a two-component system. Recently, we have characterised the mode of action of pimM at the molecular level, and determined the canonical binding site of this regulator as CTVGGGAWWTCCCBAG, just at the -35 hexamer of regulated promoters in $S$. natalensis (Santos-Aberturas et al. 2011b). The pimM paradigm is particularly attractive because homologous regulatory proteins have been found to be encoded in all known biosynthetic gene clusters of antifungal polyenes, and they have been shown to be functionally equivalent, to the extent that the production of PIM is restored in S. natalensis $\triangle$ pimM upon introduction of heterologous regulators of the PAS-LuxR class, such as amphRIV (amphotericin), nysRIV (nystatin) or pteF (filipin) into the strain (Santos-Aberturas et al. 2011b). Furthermore, introduction of a single copy of pimM into the amphotericinproducing strain $S$. nodosus, into the filipin-producing strain $S$. avermitilis or into the rimocidin-producing strain $S$. rimosus boosted the production of all polyenes, thus indicating that 
these regulators are fully exchangeable (Santos-Aberturas et al. 2011b). PimR and pimM act in a hierarchical way, pimR binds pim $M$ promoter and activates its transcription (Santos-Aberturas et al. 2012) and the gene product of the latter activates transcription from eight different promoters of PIM structural genes directly (Santos-Aberturas et al. 2011a) (Fig. 5).

Although pimM has been traditionally considered as a PIM-specific regulator, recent results have shown that it cannot be considered as pathway-specific but as a regulator with a wider range of implications. Its canonical operator was used to search for putative targets of orthologous protein $p t e F$ in the genome of S. avermitilis, finding 101 putative operators, 97 outside the pentaene filipin gene cluster ( $p t e$ ). These binding sites were located inside or upstream from genes involved in different aspects of both primary and secondary metabolism, including genetic information processing, DNA replication and repair, energy metabolism, carbohydrate metabolism, lipid metabolism, morphological differentiation, transcriptional regulation and secondary metabolite biosynthesis, amongst others (Fig. 5), thus suggesting that the regulator could govern those processes. Seventeen of these operators were selected, and their binding to pimM DNA-binding domain was demonstrated by EMSA (Vicente et al. 2015). As a proof of concept, the biosynthesis of the ATP-synthase inhibitor oligomycin whose gene cluster included two operators was studied. PteF mutants, which show a severe loss of filipin production and delayed spore formation in comparison to that of the wildtype strain (Vicente et al. 2014), also showed a severe loss of oligomycin production and reduced expression of olm genes, whereas gene complementation of the mutant restored phenotype, thus demonstrating that $p t e F$ was able to co-regulate the biosynthesis of two related secondary metabolites, filipin and oligomycin. This cross regulation could therefore be extended to all the processes indicated above, which suggests that PASLuxR regulators affect a plethora of processes previously unforeseen.

\section{Global regulatory mechanisms}

The biosynthesis of PIM in $S$. natalensis is very sensitive to repression by inorganic phosphate. Concentrations as low as $2 \mathrm{mM}$ are sufficient to block PIM production. This negative effect is exerted at the transcription level (Mendes et al. 2007b). The cellular response to phosphate scarcity is driven by the two-component system phoR-phoP. PhoR is a membrane-bound sensor kinase, and $p h o P$ is a DNAbinding response regulator that controls transcription of target genes known as the pho regulon. DNA binding of phosphorylated $p h o P$ to its operators (PHO boxes) takes place following phosphate depletion. The phoU-phoR-phoP region of S. natalensis has been characterised (Mendes et al. 2007b). The phoP protein from S. coelicolor binds to PHO box consensus sequences in the $S$. natalensis phoU-phoRP intergenic
Fig. 5 Model of PIM regulation. Proposed model for gene expression activation by the cluster-situated regulators pimR and pimM. The pointed boxes indicate the direction of transcription of pim genes. The transcriptional regulators are indicated in red, the PKS genes are shown in green and the remaining genes in orange. Dashed lines represent transcription and translation of regulatory genes. Numbers indicate the order of events. Continuous black arrows indicate direct transcriptional activation, whereas the dotted arrow indicates indirect activation. Bent arrows below the genes indicate transcriptional units. The blue line indicates other processes directly affected by pimM (Vicente et al. 2015)

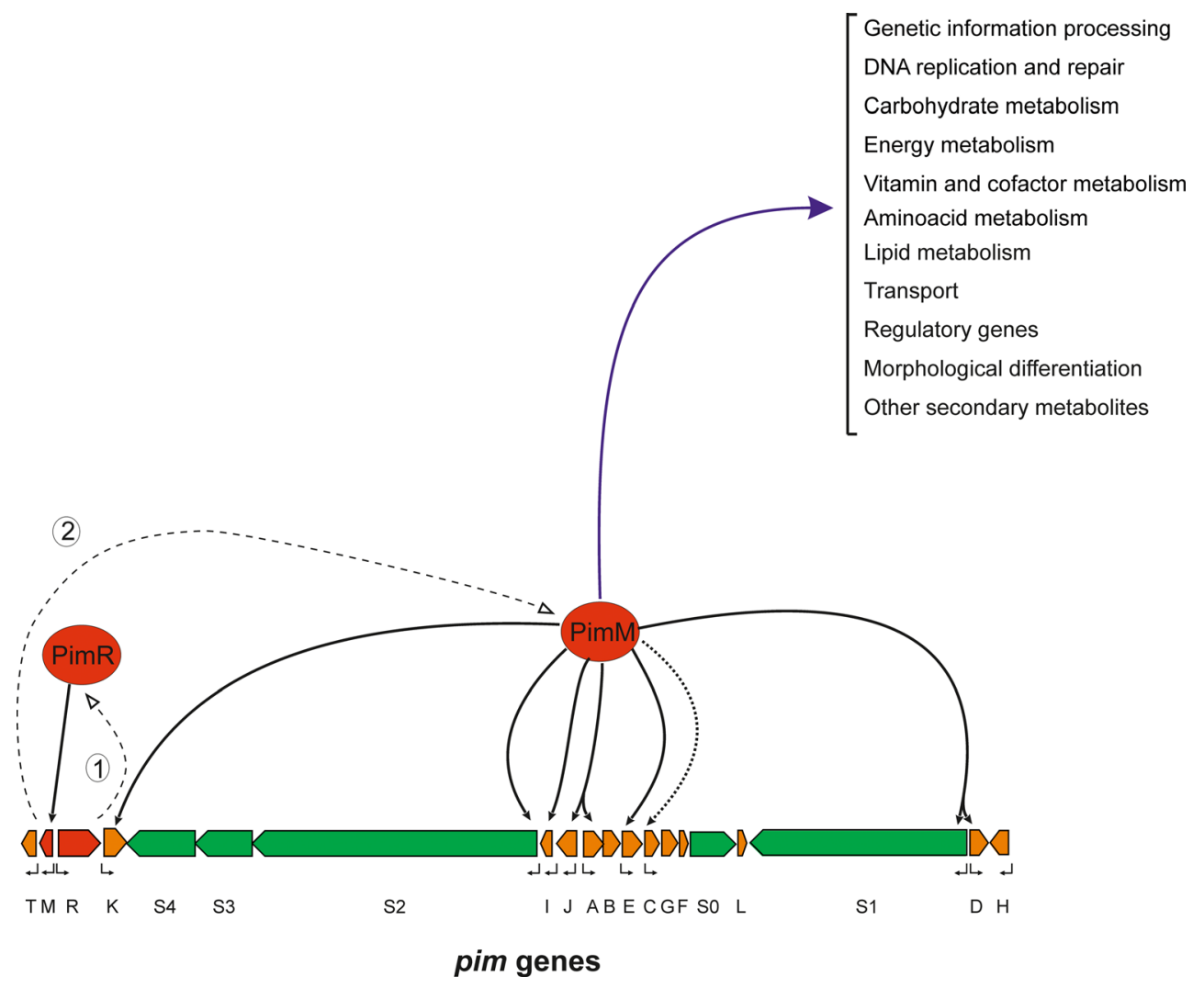


region, indicating that the system is autoregulated. Several pim genes showed increased expression in the $p h o P$-disrupted mutant, but no consensus PHO boxes were found in the whole pim cluster, suggesting that phosphate control of these genes is mediated by $p h o P$ via other regulators.

Another pleiotropic regulator which positively regulates PIM production by direct binding to the promoters of structural genes has been described in S. chattanoogensis. WhiG binds to the promoters of $s c n C$ and $s c n D$ (homologues to $\operatorname{pim} C$ and pimD, respectively) (Liu et al. 2015a). This regulator also acts as an activator of scnRI and scnRII transcription (orthologues of pimR and pimM, respectively), although in this case indirectly (Liu et al. 2015a).

Other wide domain regulators that have been involved in indirect PIM regulation are the $a d p A$ pleiotropic regulator, which has been shown to act as a positive regulator of PIM production in S. chattanoogensis (Du et al. 2011a), and one of its direct targets wblA (Yu et al. 2014).

PIM production is an aerobic process and thus positively affected by oxygen availability. However, high levels of molecular oxygen consumption can lead to the formation of reactive oxygen species (ROS) that can damage cell components. The redox-based regulation network triggered by an imbalance of the intracellular ROS homeostasis, in particular intracellular $\mathrm{H}_{2} \mathrm{O}_{2}$ levels, is also able to modulate the biosynthesis of PIM in S. natalensis (Beites et al. 2011). Inactivation of superoxide dismutase $s o d F$ leads to reduced PIM production, whilst suppression of the $\mathrm{H}_{2} \mathrm{O}_{2}$-detoxifying enzymes like the alkyl hydroperoxidase system $a h p C D$ or the catalase katA1 provokes a PIM overproducer phenotype (Table 2), thus suggesting a positive correlation between intracellular $\mathrm{H}_{2} \mathrm{O}_{2}$ and PIM production (Beites et al. 2011). Recently, a cross talk between phosphate metabolism and oxidative stress in S. natalensis has been unveiled by transcriptome analysis. Deletion of either $s o d F$ or $a h p C D$ causes a delay on the transcriptional activation of the pim cluster, most likely attributable to a delay on Pi exhaustion in the culture broth. Additionally, these authors have identified cellular NADPH/ NADH ratio and the availability of biosynthetic precursors via the branched chain amino acid metabolism as the main PIM biosynthetic bottlenecks under oxidative stress conditions (Beites et al. 2014).

\section{Quorum-sensing signals}

Quorum sensing is a communication mechanism that allows bacteria to detect a high density of population and react by different mechanisms of adaptation. Growing cells produce extracellular signals (often called autoinducers) that are detected by the remaining cells of the culture, which in turn respond to this stimulus by the transcription or repression of given genes. In Streptomyces sp., both morphological differentiation and secondary metabolite biosynthesis are controlled by quorum-sensing signals that act at nanomolar concentrations.

Streptomyces use $\gamma$-butyrolactones (2,3-di-substituted- $\gamma$ butyrolactones) (GBL) as autoinducers (Fig. 6), and the signal transduction is mediated by the interaction of these autoregulators with cognate receptors which causes the receptor to dissociate from the DNA, which in turn allows transcription of the target genes. Thus, GBL receptors are transcriptional regulators belonging to the tetR superfamily of transcriptional factors (Gottelt et al. 2012).

GBL receptor proteins have been reported in $S$. natalensis $(\operatorname{sngR})$ (Lee et al. 2005) and in S. chattanoogensis (scgR) (Du et al. 2011b). A GBL receptor homologue, sprA, has also been described in S. chattanoogensis (Zhou et al. 2015). Both sngR and $\operatorname{spr} A$, but not $s c g R$, have been described to act as positive regulators of both antifungal production and morphological differentiation (Lee et al. 2005; Zhou et al. 2015). Typically, a gene located immediately upstream and divergently from the GBL receptor encoding gene codes for the GBL synthase. Such situation has been described also in $S$. natalensis (sngA) (Lee et al. 2008) and S. chattanoogensis (scgA) (Du et al. 2011b). In the case of $S$. chattanoogensis, the product of a second gene immediately downstream from $\operatorname{scg} A, \operatorname{scg} X$, is also involved in GBL biosynthesis (Du et al. 2011b). The inactivation of either of the synthases $s n g A$ or $s c g A$ leads to a decrease in PIM production and a delay in morphological differentiation (Lee et al. 2008; Zhou et al. 2015) that has to be attributed to a reduction of a putative GBL in the cells. However, a true GBL was never found in $S$. natalensis (Recio et al. 2004) or S. chattanoogensis (Du et al. 2011b).

In $S$. natalensis, although we have not been able to detect any GBL, we discovered an inducing compound of a novel class (PI factor; 2,3-diamino-2,3-bis(hydroxymethyl)-1,4butanediol) (Fig. 6) (Recio et al. 2004). PI factor elicits polyene production in S. natalensis mutants that had lost their ability to produce PIM at nanomolar concentrations in a manner characteristic of quorum sensing (Recio et al. 2004). The compound is exported out of the cells by the amino acid exporter pimT, and in contrast to GBLs, it is thought to be recognised at the membrane level and not intracellularly (Vicente et al. 2009). However, the exact mechanism remains unknown. Studies of PI factor have been limited by access to pure preparations of the compound. Recently, a chemical synthesis method has been reported (Morin and Sello 2010) that will permit future studies. Interestingly, $S$. natalensis seems to be able to integrate different quorum signals since A-factor from $S$. griseus (a well-known autoregulator of the GBL class) also triggers PIM production in the mutants (Recio et al. 2004).

Glycerol, ethylene glycol and 1,2 or 1,3-propanediol (Fig. 6) have also been described to elicit the production of PIM in S. natalensis although at higher concentrations than PI factor (Recio et al. 2006). Interestingly, glycerol also stimulated the 
Table 2 PIM production improvement strategies and yield

\begin{tabular}{|c|c|c|c|}
\hline Strategy & Strain & Yield $(\%)$ & Reference \\
\hline PimM overexpression (NP) & S. natalensis & 240 & Antón et al. 2007 \\
\hline ScnRII overexpression (NP) & S.chattanoogensis & 460 & Du et al. 2009 \\
\hline $\operatorname{Sln} M$ overexpression (NP) & S. lydicus & 190 & Wu et al. 2014 \\
\hline $\operatorname{Sln} M$ overexpression $\left(\operatorname{ermE}^{*} \mathrm{P}\right)$ & S. lydicus & 240 & Wu et al. 2014 \\
\hline $\operatorname{Sln} M$ overexpression $\left(\mathrm{NP}+e r m E^{*} \mathrm{P}\right)$ & S. lydicus & 300 & Wu et al. 2014 \\
\hline Sng $A$ overexpression (NP) & S. natalensis & 170 & Lee et al. 2008 \\
\hline WblA overexpression $($ ermE* $\mathrm{P})$ & S.chattanoogensis & 130 & Yu et al. 2014 \\
\hline WhiG overexpression (ermE* $\mathrm{P})$ & S.chattanoogensis & 126 & Liu et al. $2015 \mathrm{a}$ \\
\hline SchPPT overexpression $\left(\operatorname{ermE}^{*} \mathrm{P}\right)$ & S.chattanoogensis & 140 & Jiang et al. $2013 \mathrm{a}, \mathrm{b}$ \\
\hline SngR deletion & S. natalensis & 460 & Lee et al. 2005 \\
\hline PhoRP deletion & S. natalensis & 180 & Mendes et al. 2007b \\
\hline$A h p C D$ deletion & S. natalensis & 130 & Beites et al. 2011 \\
\hline KatA1 deletion & S. natalensis & 156 & Beites et al. 2011 \\
\hline Glycerol addition (100 mM) & S. natalensis & 250 & Recio et al. 2006 \\
\hline Pi factor addition (300 nM) & S. natalensis & 133 & Recio et al. 2004 \\
\hline Acetate:propionate addition $(7: 1)(2 \mathrm{~g} / \mathrm{L})$ & S. natalensis & 250 & Elsayed et al. 2013 \\
\hline Propanol addition $(0.2 \%)$ & S. natalensis & 117 & Li et al. 2014 \\
\hline Genome shuffling & S. gilvosporeus & 197 & Luo et al. 2012 \\
\hline Integration of $v g b$ gene & S. gilvosporeus & 407 & Wang et al. $2014 \mathrm{~b}$ \\
\hline Aspergillus niger extracellular extract & S. natalensis & 250 & Wang et al. 2013 \\
\hline Penicillium chrysogenum extracellular extract & S. natalensis & 300 & Wang et al. 2013 \\
\hline
\end{tabular}

The maximum yield is indicated $N P$ native promoter production of seven different polyene macrolides by their respective producer strains, including $S$. noursei (nystatin), S. rimosus (rimocidin), S. griseus (candicidin), S. filipinensis (filipin), S. albulus (tetrafungin), S. eurocidicus (eurocidin) and S. cinnamoneum (fungichromin). Although the exact mechanism remains unknown, the action of glycerol seems to be independent of PI factor-inducing effect (Recio et al. 2006).

\section{Cholesterol oxidase}

All the gene clusters for small-sized polyenes described up to date contain a cholesterol oxidase-encoding gene. These are

Fig. 6 Quorum-sensing signals involved in PIM biosynthesis
pimE and scnE in the case of PIM (Aparicio et al. 2000; Du et al. 2011a), tetrO in the case of tetramycin (Cao et al. 2012), pte $G$ and $f i l G$ in the case of filipin (Ikeda et al. 2003; Payero et al. 2015) and rimD in the case of rimocidin/CE-108 (Seco et al. 2004). Cholesterol oxidases (3b-hydroxysterol oxidases; EC 1.1.3.6) are flavoproteins that catalyse both the oxidation of cholesterol to 5-cholesten-3-one with the reduction of molecular oxygen to hydrogen peroxide and the isomerisation of the $\Delta^{5}$ bond to yield 4-cholesten-3-one as the final product. This enzyme participates in the initial step in the degradation of cholesterol (or other sterols with a $3-\beta$-hydroxyl group) as a carbon and energy source for growth of different bacteria but<smiles>NC(CO)(CO)C(N)(CO)CO</smiles><smiles>[R]C(O)C1C(=O)OCC1CO</smiles>

PI factor $\gamma$-butyrolactone<smiles>OCC(O)CO</smiles><smiles>OCCO</smiles><smiles>OCCCO</smiles><smiles>CC(O)CO</smiles> 
had no obvious role in antifungal production (Aparicio and Martín 2008).

In $S$. natalensis, functional analysis studies led to the surprising finding that pimE is essential for the biosynthesis of PIM. This extracellular enzyme, or other cholesterol oxidases, was shown to restore PIM production when added to knockout mutant culture broths or 'resting cells' (Mendes et al. 2007a). Hence, it has been proposed that these enzymes could act as fungal sensors, probably via ergosterol detection and in response trigger, by an unknown mechanism, antifungal production. This would confer a selective advantage on the producing organisms, which are soil dwellers, against their fungal competitors with ergosterol-containing membranes (Aparicio and Martín 2008).

\section{Production improvement strategies}

At industrial scale, PIM is produced by fermentation, which requires microbial strains producing high titres of the compound. Given that wild-type strains isolated from nature produce only discrete amounts of PIM, this implies the need for production improvement to meet commercial requirements. This has been traditionally achieved by sequential rounds of random mutation and selection, but the knowledge gained during the last years has provided new tools for a more rational way of yield improvement.

Different approaches have been used to increase PIM production yield. These studies include optimisation of medium composition (Farid et al. 2000; Chen et al. 2008), improvement of cultivation conditions (El-Enshasy et al. 2000; Liang et al. 2008) and strain gene manipulation. One of the most straightforward ways to improve metabolite production by gene manipulation is the overexpression of poorly expressed activators, and that turned out to be the case of $\operatorname{pim} M$ in S. natalensis. Gene dosage increment of pimM by using integrative vectors resulted in increased PIM production, thus suggesting that its expression constitutes a bottleneck for antifungal production (Antón et al. 2007). Moreover, PAS-LuxR regulators are functionally equivalent, to the extent that introduction of a single copy of pimM (or other PAS-LuxR regulator) into the chromosome of a given polyene producer boosts the production of the corresponding polyene (SantosAberturas et al. 2011b). These findings constituted the first report of a general mechanism regulating polyene production, and established the rationale for enhancement of PIM, and other polyene production in different producers of these antifungals (Du et al. 2009; Wei et al. 2011; Wu et al. 2014). Improvement in production varied between strains and the production medium used but ranged from $40 \%$ in the rimocidin producer $S$. rimosus (Santos-Aberturas et al. 2011 b) to $460 \%$ in the PIM producer $S$. chattanoogensis (Du et al. 2009) (Table 2). These strategies for production improvement have used the native promoter of the PAS-LuxR gene, but the use of constitutive promoters such as $e r m E^{*} p$ instead of the original promoter, and in addition to the native promoter (double promoter), have also been described with improved results (Wei et al. 2011; Wu et al. 2014).

Other strategies reported for production improvement have included the overexpression of phosphopantetheinyl transferases (Jiang et al. 2013a, b), the GBL synthase $\operatorname{sig} A$ (Lee et al. 2008) and pleiotropic regulators such as whiG (Liu et al. 2015a) or wblA (Yu et al. 2014) or deletion of the twocomponent system phoRP (Mendes et al. 2007b) and the GBL receptor sngR (Lee et al. 2005) (Table 2).

The addition of short-chain carboxylic acids has also been reported to increase PIM yield and also to shorten production time. Acetic and propionic acids were particularly stimulatory in $S$. natalensis cultures, especially when added together in a 7:1 ratio (total concentration $2 \mathrm{~g} / \mathrm{L}$ ) (Elsayed et al. 2013). This makes sense since these compounds are precursors of polyketide biosynthesis. Similarly, propanol has also been reported as stimulatory (Li et al. 2014) (Table 2).

Other successful strategies used included genome shuffling by recursive protoplast fusion, reaching increments of $97 \%$ in comparison with the parental strain (Luo et al. 2012), the chromosomal integration of the Vitreoscilla hemoglobin $v g b$ gene, which rendered a maximum of $407 \%$ increase depending on the growth conditions (Wang et al. 2014b), or the use of fungal elicitors present in extracellular extracts of $A$. niger and in particular of $P$. chrysogenum (Wang et al. 2013) (Table 2).

\section{Prospects}

Amongst the major applications of PIM, its use as a natural food antimicrobial is generalised worldwide, being used in more than 150 countries. PIM has been used for more than 40 years now and continues to constitute a gold standard in the preservation of foods and beverages against mould spoilage and the inherent risk of mycotoxin poisoning. Its broad spectrum of activity against almost every type of fungi but not bacteria, its lack of effect on the quality of food, its low likelihood of causing microbial resistance and especially its safeness for consumption have made this molecule an ideal biopreservative. Thus, its use that was initially restricted to the surface treatment of some types of cheese has expanded exponentially to other foods, beverages, storage facilities and even some crops. Furthermore, the increasing demand of healthy processed foods and beverages with natural antimicrobials as alternatives to physical- and chemical-based antimicrobial treatments ensures that PIM use will continue growing in the future.

Thanks to the advances in the genetic manipulation of PIM producers and the considerable progress in the knowledge about the regulation of PIM production; several PIM derivatives with improved properties have been developed, and many of the bottlenecks hampering PIM production at high 
titres have been overcome. The future application of this knowledge at the industrial scale will hopefully permit to satisfy the growing PIM commercial demands. In this sense, the present availability of the genome sequences of PIM producers such as $S$. natalensis (GenBank JRKI01; Beites et al. 2015) and S. chattanoogensis (GenBank LGKG01) will certainly constitute a very valuable tool in the efforts to improve PIM production.

\section{Compliance with ethical standards}

Funding This work was supported by the Spanish Ministerio de Economía y Competitividad (Grant BIO2013-42983-P to JFA); F.P.U. fellowships from the Ministerio de Educación, Cultura y Deporte (AP2005-3644 to JSA, AP2007-02055 to TDP and FPU13/01537 to AP), a contract from the Junta de Castilla y León co-financed by the European Social Fund (to EGB); and a fellowship from the Portuguese Fundação para a Ciência e a Tecnologia (SFRH/BD/64006/2009 to CMV).

Conflict of interest The authors declare that they have no conflict of interest.

Ethical approval This article does not contain any studies with human participants or animals performed by any of the authors.

Open Access This article is distributed under the terms of the Creative Commons Attribution 4.0 International License (http:// creativecommons.org/licenses/by/4.0/), which permits unrestricted use, distribution, and reproduction in any medium, provided you give appropriate credit to the original author(s) and the source, provide a link to the Creative Commons license, and indicate if changes were made.

\section{References}

Ansari Z, Miller D, Galor A (2013) Current thoughts in fungal keratitis: diagnosis and treatment. Curr Fungal Infect Rep 7:209-218. doi:10. 1007/s12281-013-0150-110. 1007/s12281-013-0150-1

Antón N, Mendes MV, Martín JF, Aparicio JF (2004) Identification of PimR as a positive regulator of pimaricin biosynthesis in Streptomyces natalensis. J Bacteriol 186:2567-2575. doi:10.1128/ JB.186.9.2567-2575.2004

Antón N, Santos-Aberturas J, Mendes MV, Guerra SM, Martín JF, Aparicio JF (2007) PimM, a PAS domain positive regulator of pimaricin biosynthesis in Streptomyces natalensis. Microbiology 53:3174-3183. doi:10.1099/mic.0.2007 /009126-0

Aparicio JF, Martín JF (2008) Microbial cholesterol oxidases: bioconversion enzymes or signal proteins? Mol Biosyst 4:804-809. doi:10. 1039/b717500k

Aparicio JF, Colina AJ, Ceballos E, Martín JF (1999) The biosynthetic gene cluster for the 26-membered ring polyene macrolide pimaricin: a new polyketide synthase organization encoded by two subclusters separated by functionalization genes. J Biol Chem 274:1013310139. doi:10.1074/jbc.274.15.10133

Aparicio JF, Fouces R, Mendes MV, Olivera N, Martín JF (2000) A complex multienzyme system encoded by five polyketide synthase genes is involved in the biosynthesis of the 26-membered polyene macrolide pimaricin in Streptomyces natalensis. Chem Biol 7:895905. doi:10.1016/S1074-5521(00)00038-7
Aparicio JF, Caffrey P, Gil JA, Zotchev SB (2003) Polyene antibiotic biosynthesis gene clusters. Appl Microbiol Biotechnol 61:179188. doi:10.1007/s00253-002-1183-5

Aparicio JF, Mendes MV, Antón N, Recio E, Martín JF (2004) Polyene macrolide antibiotic biosynthesis. Curr Med Chem 11:1645-1656. doi: $10.2174 / 0929867043365044$

Arima AA, Pavinatto FJ, Oliveira ON Jr, Gonzales ERP (2014) The negligible effects of the antifungal natamycin on cholesteroldipalmitoyl phosphatidylcholine monolayers may explain its low oral and topical toxicity for mammals. Colloids Surf B: Biointerfaces 122:202-208. doi:10.1016/j.colsurfb.2014.06.058

Baginski M, Resat H, McCammon JA (1997) Molecular properties of amphotericin B membrane channel: a molecular dynamics simulation. Mol Pharmacol 52:560-570. doi:10.1124/mol.52.4.560

Baginski M, Czub J, Sternal K (2006) Interaction of amphotericin B and its selected derivatives with membranes: molecular modeling studies. Chem Rec 6:320-332. doi:10.1002/tcr.20096

Beites T, Pires SD, Santos CL, Osório H, Moradas-Ferreira P, Mendes MV (2011) Crosstalk between ROS homeostasis and secondary metabolism in S. natalensis ATCC 27448: modulation of pimaricin production by intracellular ROS. PLoS One 6, e27472. doi:10.1371/ journal.pone. 0027472

Beites T, Rodríguez-García A, Santos-Beneit F, Moradas-Ferreira P, Aparicio JF, Mendes MV (2014) Genome-wide analysis of the regulation of pimaricin production in Streptomyces natalensis by reactive oxygen species. Appl Microbiol Biotechnol 98:2231-2241. doi: 10.1007/s00253-013-5455-Z

Beites T, Oliveira P, Rioseras B, Pires SD, Oliveira R, Tamagnini P, Moradas-Ferreira P, Manteca A, Mendes MV (2015) Streptomyces natalensis programmed cell death and morphological differentiation are dependent on oxidative stress. Sci Rep 5:12887. doi:10.1038/ srep 12887

Belakhov VV, Shenin YD, Ionin BI (2008) Synthesis of hydrophospohoryl derivatives of the antifungal antibiotic pimaricin by the Kabachnik-Fields reaction. Rus J Gen Chem 78:305-312. doi:10.1134/S1070363208020217

Belakhov VV, Shenin YD, Ionin BI (2010) Synthesis and antifungal activity of $\mathrm{N}$-aryl-substituted pimaricin derivatives. Pharma Chem J 44:486-492. doi:10.1007/s11094-010-0498-2

Bolard J (1986) How do polyene macrolide antibiotics affect the cellular membrane properties? Biochim Biophys Acta 864:257-304. doi:10. 1016/0304-4157(86)90002-X

Bonner DP, Mechlinski W, Schaffner CP (1972) Polyene macrolide derivatives. 3. Biological properties of polyene macrolide ester salts. J Antibiot 25:261-262. doi:10.7164/antibiotics.25.261

Bouaoud C, Lebouille JG, Mendes E, De Braal HE, Meesters GM (2015) Formulation and antifungal performance of natamycin-loaded liposomal suspensions: the benefits of sterol-enrichment. J Liposome Res. doi:10.3109/08982104.2015.1046079

Byrne B, Carmody M, Gibson E, Rawlings B, Caffrey P (2003) Biosynthesis of deoxyamphotericins and deoxyamphoteronolides by engineered strains of Streptomyces nodosus. Chem Biol 10: 1215-1224. doi:10.1016/j.chembiol.2003.12.001

Caffrey P, Aparicio JF, Malpartida F, Zotchev SB (2008) Biosynthetic engineering of polyene macrolides towards generation of improved antifungal and antiparasitic agents. Curr Top Med Chem 8:639-653. doi:10.2174/156802608784221479

Cañedo LM, Costa L, Criado LM, Puentes JLF, Moreno MA, Rinehart KL (2000) AB-400, a new tetraene macrolide isolated from Streptomyces costae. J Antibiot 53:623-626. doi:10.7164/ antibiotics.53.623

Cao B, Yao F, Zheng X, Cui D, Shao Y, Zhu C, Deng Z, You D (2012) Genome mining of the biosynthetic gene cluster of the polyene macrolide antibiotic tetramycin and characterization of a P450 monooxygenase involved in the hydroxylation of the tetramycin $\mathrm{B}$ 
polyol segment. Chembiochem 13:2234-2242. doi:10.1002/cbic. 201200402

Cevher E, Sensoy D, Zloh M, Mülazimoğlu L (2008) Preparation and characterisation of natamycin: gamma-cyclodextrin inclusion complex and its evaluation in vaginal mucoadhesive formulations. J Pharm Sci 97:4319-4335. doi:10.1002/jps.21312

Chen GQ, Lu FP, Du LX (2008) Natamycin production by Streptomyces gilvosporeus based on statistical optimization. J Agric Food Chem 56:5057-5061. doi:10.1021/jf800479u

Copping LG, Duke SO (2007) Natural products that have been used commercially as crop protection agents. Pest Manag Sci 63:524 554. doi:10.1002/ps.1378

Darisipudi MN, Allam R, Rupanagudi KV, Anders HJ (2011) Polyene macrolide antifungal drugs trigger interleukin- $1 \beta$ secretion by activating the NLRP3 inflammasome. PLoS One 6, e19588. doi:10. 1371/journal.pone.0019588

de Kruijff B, Demel RA (1974) Polyene antibiotic-sterol interactions in membranes of Acholeplasma laidlawii cells and lecithin liposomes. III. Molecular structure of the polyene antibiotic-cholesterol complexes. Biochim Biophys Acta 339:57-70. doi:10.1016/00052736(74)90332-0

de Oliveira TM, Soares NF, Pereira RM, Fraga KF (2007) Development and evaluation of antimicrobial natamycin-incorporated film in gorgonzola cheese conservation. Packag Technol Sci 20:147-153. doi: $10.1002 /$ pts. 756

de Vries RP, de Lange ES, Wösten HA, Stalpers JA (2008) Control and possible applications of a novel carrot-spoilage basidiomycete, Fibulorhizoctonia psychrophila. Antonie Van Leeuwenhoek 93: 407-413. doi:10.1007/s10482-007-9218-7

Du YL, Chen SF, Cheng LY, Shen XL, Tian Y, Li YQ (2009) Identification of a novel Streptomyces chattanoogensis L10 and enhancing its natamycin production by overexpressing positive regulator ScnRII. J Microbiol 47:506-513. doi:10.1007/s12275-0090014-0

Du YL, Li SZ, Zhou Z, Chen SF, Fan WM, Li YQ (2011a) The pleitropic regulator AdpAch is required for natamycin biosynthesis and morphological differentiation in Streptomyces chattanoogensis. Microbiology 157:1300-1311. doi:10.1099/mic.0.046607-0

Du YL, Shen XL, Yu P, Bai LQ, Li YQ (2011b) Gamma-butyrolactone regulatory system of Streptomyces chattanoogensis links nutrient utilization, metabolism, and development. Appl Environ Microbiol 77:8415-8426. doi:10.1128/AEM.05898-11

Edelstein PH, Edelstein MA (1996) Natamycin as a selective antifungal agent in media for growth of Legionella spp. J Clin Microbiol 34: $185-187$

el-Enshasy HA, Farid MA, el-Sayed e-SA (2000) Influence of inoculum type and cultivation conditions on natamycin production by Streptomyces natalensis. J Basic Microbiol 40:333-342. doi:10. 1002/1521-4028(200012)40:5/6<333::AID-JOBM333>3.3. $\mathrm{CO} ; 2-\mathrm{H}$

Elsayed EA, Farid MA, el-Enshasy HA (2013) Improvement in natamycin production by Streptomyces natalensis with the addition of short-chain carboxylic acids. Proc Biochem 48:1831-1838. doi: 10.1016/j.procbio.2013.09.009

Enríquez LL, Mendes MV, Antón N, Tunca S, Guerra SM, Martín JF, Aparicio JF (2006) An efficient gene transfer system for the pimaricin producer Streptomyces natalensis. FEMS Microbiol Lett 257:312-318. doi:10.1111/j.1574-6968.2006.00189.x

Fajardo P, Martins JT, Fucinos C, Pastrana L, Teixeira JA, Vicente AA (2010) Evaluation of a chitosan-based edible film as carrier of natamycin to improve the storability of Saloio cheese. J Food Eng 101:349-356. doi:10.1016/j.jfoodeng.2010.06.029

Falkowski L, Stefanska B, Zielinski J, Bylec E, Golik J, Kolodziejczyk P, Borowski E (1979) Methyl esters of trimethyl-ammonium derivatives of polyene macrolide antibiotics. J Antibiot 32:1080-1081. doi:10.7164/antibiotics.32.1080
Falkowski L, Zieliński J, Pawlak J, Golik J, Kołodziejczyk P, Stefańska B, Bylec E, Borowski E (1980) The preparation of N-glycosyl derivatives of polyene macrolide antibiotics and their comparative antifungal activities. Acta Pol Pharm 37:517-520

Farid MA, el-Enshasy HA, el-Diwany AI, el-Sayed el-S A (2000) Optimization of the cultivation medium for natamycin production by Streptomyces natalensis. J Basic Microbiol 40:157-166. doi:10. 1002/1521-4028(200007)40:3<157::AID-JOBM157>3.0.CO;2-1

Fujii G, Chang JE, Coley T, Steere B (1997) The formation of amphotericin B ion channels in lipid bilayers. Biochemistry 36 : 4959-4968. doi:10.1021/bi962894z

Golding BT, Rickards RW, Meyer WE, Patrick JB, Barber M (1966) Structure of macrolide antibiotic pimaricin. Tetrahedron Lett 30: 3551-3557

Gottelt M, Hesketh A, Bunet R, Puri P, Takano E (2012) Characterisation of a natural variant of the $\gamma$-butyrolactone signalling receptor. BMC Res Notes 5:379. doi:10.1186/1756-0500-5-379

Guerra SM, Rodríguez-García A, Santos-Aberturas J, Vicente CM, Payero TD, Martín JF, Aparicio JF (2012) LAL regulators SCO0877 and SCO7173 as pleiotropic modulators of phosphate starvation response and actinorhodin biosynthesis in Streptomyces coelicolor. PLoS One 7, e31475. doi:10.1371/journal.pone.0031475

Hanusová K, Stastna M, Votavova L, Klaudisova K, Dobias J, Voldrich M, Marek M (2010) Polymer films releasing nisin and/or natamycin from polyvinyldichloride lacquer coating: nisin and natamycin migration, efficiency in cheese packaging. J Food Eng 99:491-496. doi:10.1016/j.jfoodeng.2010.01.034

He X, Li R, Pan Y, Liu G, Tan H (2010) SanG, a transcriptional activator, controls nikkomycin biosynthesis through binding to the $\operatorname{sanN}$ sanO intergenic region in Streptomyces ansochromogenes. Microbiology 156:828-837. doi:10.1099/mic.0.033605-0

Hefti MH, Francoijs K-J, de Vries SC, Dixon R, Vervoort J (2004) The PAS fold. A redefinition of the PAS domain based upon structural prediction. Eur J Biochem 271:1198-1208. doi:10.1111/j.14321033.2004.04023.x

Heese-Peck A, Pichler H, Zanolari B, Watanabe R, Daum G, Riezman H (2002) Multiple functions of sterols in yeast endocytosis. Mol Biol Cell 13:2664-2680. doi:10.1091/mbc.E02-04-0186

Hondrodimou O, Kourkoutas Y, Panagou EZ (2011) Efficacy of natamycin to control fungal growth in natural black olive fermentation. Food Microbiol 28:621-627. doi:10.1016/j.fm.2010.11.015

Hsiao CH, Yeh LK, Chen HC, Lin HC, Chen PY, Ma DH, Tan HY (2014) Clinical characteristics of Alternaria keratitis. J Ophthalmol 2014: 536985. doi:10.1155/2014/536985

Ikeda H, Ishikawa J, Hanamoto A, Shinose M, Kikuchi H, Shiba T, Sakaki Y, Hattori M, Omura S (2003) Complete genome sequence and comparative analysis of the industrial microorganism Streptomyces avermitilis. Nat Biotechnol 21:526-531. doi:10. $1038 / \mathrm{nbt} 820$

Jiang H, Wang YY, Ran XX, Fan WM, Jiang XH, Guan WJ, Li YQ (2013a) Improvement of natamycin production by engineering of phosphopantetheinyl transferases in Streptomyces chattanoogensis L10. Appl Environ Microbiol 79:3346-3354. doi:10.1128/AEM. 00099-13

Jiang T, Feng L, Zheng X, Li J (2013b) Physicochemical responses and microbial characteristics of shiitake mushroom (Lentinus edodes) to gum arabic coating enriched with natamycin during storage. Food Chem 138:1992-1997. doi:10.1016/j.foodchem.2012.11.043

Jin H, McCaffery JM, Grote E (2008) Ergosterol promotes pheromone signaling and plasma membrane fusion in mating yeast. J Cell Biol 180:813-826. doi:10.1083/jcb.200705076

Juneja VK, Dwivedi HP, Yan X (2012) Novel natural food antimicrobials. Annu Rev Food Sci Technol 3:381-403. doi:10.1146/annurev-food022811-101241

Kaliamurthy J, Kalavathy CM, Ramalingam MD, Prasanth DA, Jesudasan CA, Thomas PA (2004) Keratitis due to a coelomycetous 
fungus: case reports and review of the literature. Cornea 23:3-12. doi:10.1097/00003226-200401000-00002

Kato M, Wickner W (2001) Ergosterol is required for the Sec18/ATPdependent priming step of homotypic vacuole fusion. EMBO J 20: 4035-4040. doi:10.1093/emboj/20.15.4035

Kells PM, Ouellet H, Santos-Aberturas J, Aparicio JF, Podust LM (2010) Structure of cytochrome P450 PimD suggests epoxidation of the polyene macrolide pimaricin occurs via a hydroperoxoferric intermediate. Chem Biol 17:841-851. doi: 10.1016/j.chembiol.2010.05.026

Knopik-Skrocka A, Bielawski J (2002) The mechanism of the hemolytic activity of polyene antibiotics. Cell Mol Biol Lett 7:31-48

Kong D, Lee MJ, Lin S, Kim ES (2013) Biosynthesis and pathway engineering of antifungal polyene macrolides in actinomycetes. J Ind Microbiol Biotechnol 40:529-543. doi:10.1007/s10295013-1258-6

Lalitha P, Shapiro BL, Srinivasan M, Prajna NV, Acharya NR, Fothergill AW, Ruiz J, Chidambaram JD, Maxey KJ, Hong KC, McLeod SD, Lietman TM (2007) Antimicrobial susceptibility of Fusarium, Aspergillus, and other filamentous fungi isolated from keratitis. Arch Ophthalmol 125:789-793. doi:10.1001/archopht.125.6.789

Lancelin JM, Beau JM (1990) Stereostructure of pimaricin. J Am Chem Soc 112:4060-4061. doi:10.1021/ja00166a065

Lee KM, Lee CK, Choi SU, Park HR, Kitani S, Nihira T, Hwang YI (2005) Cloning and in vivo functional analysis by disruption of a gene encoding the gamma-butyrolactone autoregulator receptor from Streptomyces natalensis. Arch Microbiol 184:249-257. doi: 10.1007/s00203-005-0047-7

Lee KM, Lee CK, Choi SU, Park HR, Hwang YI (2008) Functional analysis of a BarX homologue (SngA) as a pleiotropic regulator in Streptomyces natalensis. Arch Microbiol 189:569-577. doi:10. 1007/s00203-008-0349-7

Li M, Chen S, Li J, Ji Z (2014) Propanol addition improves natamycin biosynthesis of Streptomyces natalensis. Appl Biochem Biotechnol 172:3424-3432. doi:10.1007/s12010-014-0766-9

Li R, Xie Z, Tian Y, Yang H, Chen W, You D, Liu G, Deng Z, Tan H (2009) polR, a pathway-specific transcriptional regulatory gene, positively controls polyoxin biosynthesis in Streptomyces cacaoi subsp. asoensis. Microbiology 155:1819-1831. doi:10.1099/mic.0. 028639-0

Liang J, Xu Z, Liu T, Lin J, Cen P (2008) Effects of cultivation conditions on the production of natamycin with Streptomyces gilvosporeus LK196. Enzyme Microb Technol 42:145-150. doi:10.1016/j. enzmictec.2007.08.012

Liu G, Tian Y, Yang H, Tan H (2005) A pathway-specific transcriptional regulatory gene for nikkomycin biosynthesis in Streptomyces ansochromogenes that also influences coloy development. Mol Microbiol 55:1855-1866. doi:10.1111/j.1365-2958.2005.04512.x

Liu G, Chater KF, Chandra G, Niu G, Tan H (2013) Molecular regulation of antibiotic biosynthesis in Streptomyces. Microbiol Mol Biol Rev 77:112-143. doi:10.1128/MMBR.00054-12

Liu SP, Yu P, Yuan PH, Zhou ZX, Bu QT, Mao XM, Li YQ (2015a) Sigma factor WhiGch positively regulates natamycin production in Streptomyces chattanoogensis L10. Appl Microbiol Biotechnol 99: 2715-2726. doi:10.1007/s00253-014-6307-1

Liu SP, Yuan PH, Wang YY, Liu XF, Zhou ZX, Bu QT, Yu P, Jiang H, Li YQ (2015b) Generation of the natamycin analogs by gene engineering of natamycin biosynthetic genes in Streptomyces chattanoogensis L10. Microbiol Res 173:25-33. doi:10.1016/j. micres.2015.01.013

Lu CG, Liu WC, Qiu JY, Wang HM, Liu T, De Liu W (2008) Identification of an antifungal metabolite produced by a potential biocontrol Actinomyces strain A01. Braz J Microbiol 39:701-707. doi:10.1590/S1517-838220080004000020

Luo JM, Li JS, Liu D, Liu F, Wang YT, Song XR, Wang M (2012) Genome shuffling of Streptomyces gilvosporeus for improving natamycin production. J Agric Food Chem 60:6026-6036. doi:10. 1021/jf300663w

Mann DA, Beuchat LR (2008) Combinations of antimycotics to inhibit the growth of molds capable of producing 1,3-pentadiene. Food Microbiol 25:144-153. doi:10.1016/j.fm.2007.06.005

Martin SW, Konopka JB (2004) Lipid raft polarization contributes to hyphal growth in Candida albicans. Eukaryotic Cell 3:675-684. doi:10.1128/EC.3.3.675-684.2004

Martín JF, Aparicio JF (2009) Enzymology of the polyenes pimaricin and candicidin biosynthesis. Methods Enzymol 459:215-242. doi:10. 1016/S0076-6879(09)04610-2

Medina A, Jiménez M, Mateo R, Magan N (2007) Efficacy of natamycin for control of growth and ochratoxin A production by Aspergillus carbonarius strains under different environmental conditions. J Appl Microbiol 103:2234-2239. doi:10.1111/j.1365-2672.2007. 03462.x

Mendes MV, Recio E, Fouces R, Luiten R, Martín JF, Aparicio JF (2001) Engineered biosynthesis of novel polyenes: a pimaricin derivative produced by targeted gene disruption in Streptomyces natalensis. Chem Biol 8:635-644. doi:10.1016/S1074-5521(01)00033-3

Mendes MV, Antón N, Martín JF, Aparicio JF (2005) Characterization of the polyene macrolide P450 epoxidase from Streptomyces natalensis that converts de-epoxypimaricin into pimaricin. Biochem J 386:57-62. doi:10.1042/BJ20040490

Mendes MV, Recio E, Antón N, Guerra SM, Santos-Aberturas J, Martín JF, Aparicio JF (2007a) Cholesterol oxidases act as signaling proteins for the biosynthesis of the polyene macrolide pimaricin. Chem Biol 14:279-290. doi:10.1016/j.chembiol.2007.01.010

Mendes MV, Tunca S, Antón N, Recio E, Sola-Landa A, Aparicio JF, Martín JF (2007b) The two-component phoR-phoP system of Streptomyces natalensis: Inactivation or deletion of phoP reduces the negative phosphate regulation of pimaricin biosynthesis. Metab Eng 9:217-227. doi:10.1016/j.ymben.2006.10.003

Mendez C, Salas JA (2001) The role of ABC transporters in antibioticproducing organisms: drug secretion and resistance mechanisms. Res Microbiol 152:341-350. doi:10.1016/S0923-2508(01)01205-0

Miranzo D, Seco EM, Cuesta T, Malpartida F (2010) Isolation and characterization of $p \operatorname{cs} B$, the gene for a polyene carboxamide synthase that tailors pimaricin into AB-400. Appl Microbiol Biotechnol 85: 1809-1819. doi:10.1007/s00253-009-2195-1

Mysyakina IS, Funtikova NS (2007) The role of sterols in morphogenetic processes and dimorphism in fungi. Microbiology 76:1-13. doi:10. 1134/S0026261707010018

Möglich A, Ayers RA, Moffat K (2009) Structure and signaling mechanism of Per-ARNT-Sim domains. Structure 17:1282-1294. doi:10. 1016/j.str.2009.08.011

Morin JB, Sello JK (2010) Efficient synthesis of a peculiar vicinal diamine semiochemical from Streptomyces natalensis. Org Lett 12: 3522-3524. doi:10.1021/ol1013763

Munn AL (2001) Molecular requirements for the internalisation step of endocytosis: insights from yeast. Biochim Biophys Acta 1535:236 257. doi:10.1016/S0925-4439(01)00028-X

Nedal A, Sletta H, Brautaset T, Borgos SEF, Sekurova ON, Ellingsen TE, Zotchev SB (2007) Analysis of the mycosamine biosynthesis and attachment genes in the nystatin biosynthetic gene cluster of Streptomyces noursei ATCC 11455. Appl Environ Microbiol 73: 7400-7407. doi:10.1128/AEM.01122-07

Nic Lochlainn L, Caffrey P (2009) Phosphomannose isomerase and phosphomannomutase gene disruptions in Streptomyces nodosus: impact on amphotericin biosynthesis and implications for glycosylation engineering. Metab Eng 11:40-47. doi:10.1016/j.ymben.2008. 08.007

Nirgudkar AG, Sastry MK, Swami MB, Nanda RK (1988) Structure/ function relationship in macrolide polyene antibiotics. Hindustan Antibiotics Bulletin 30:66-71 
Paquet V, Carreira EM (2006) Significant improvement of antifungal activity of polyene macrolides by bisalkylation of the mycosamine. Org Lett 8:1807-1809. doi:10.1021/o1060353o

Patrick JB, Williams RP, Webb JS (1958) Pimaricin 2. The structure of pimaricin J Am Chem Soc 80:6689-6689. doi:10.1021/ ja01557a060

Payero TD, Vicente CM, Rumbero A, Barreales EG, Santos-Aberturas J, de Pedro A, Aparicio JF (2015) Functional analysis of filipin tailoring genes from Streptomyces filipinensis reveals alternative routes in filipin III biosynthesis and yields bioactive derivatives. Microb Cell Fact 14:114. doi:10.1186/s12934-015-0307-4

Pintado CMBS, Ferreira MASS, Sousa I (2010) Control of pathogenic and spoilage microorganisms from cheese surface by whey protein films containing malic acid, nisin and natamycin. Food Control 21: 240-246. doi:10.1016/j.foodcont.2009.05.017

Pipek P, Rohlík B-A, Lojková A, Staruch L (2010) Suppression of mould growth on dry sausages. Czech J Food Sci 28:258-263

Qi Z, Kang Q, Jiang C, Han M, Bai L (2015) Engineered biosynthesis of pimaricin derivatives with improved antifungal activity and reduced cytotoxicity. Appl Microbiol Biotechnol. doi:10.1007/s00253-0156635-9

Recio E, Colinas A, Rumbero A, Aparicio JF, Martín JF (2004) PI factor, a novel type quorum-sensing inducer elicits pimaricin production in Streptomyces natalensis. J Biol Chem 279:41586-41593. doi:10. 1074/jbc.M402340200

Recio E, Aparicio JF, Rumbero A, Martín JF (2006) Glycerol, ethylene glycol and propanediol elicit pimaricin biosynthesis in the PI-factordefective strain Streptomyces natalensis npi287 and increase polyene production in several wild-type actinomycetes. Microbiology 152:3147-3156. doi:10.1099/mic.0.28953-0

Rolón M, Seco EM, Vega C, Nogal JJ, Escario JA, Gómez-Barrio A, Malpartida F (2006) Selective activity of polyene macrolides produced by genetically modified Streptomyces on Trypanosoma cruzi. Int J Antimicrob Agents 28:104-109. doi:10.1016/j.ijantimicag. 2006.02.025

Santos CL, Correia-Neves M, Moradas-Ferreira P, Mendes MV (2012) A walk into the LuxR regulators of Actinobacteria: phylogenomic distribution and functional diversity. PLoS One 7, e46758. doi:10. 1371/journal.pone. 0046758

Santos-Aberturas J, Vicente CM, Guerra SM, Payero TD, Martín JF, Aparicio JF (2011a) Molecular control of polyene macrolide biosynthesis: direct binding of the regulator PimM to eight promoters of pimaricin genes and identification of binding boxes. J Biol Chem 286:9150-9161. doi:10.1074/jbc.M110.182428

Santos-Aberturas J, Payero TD, Vicente CM, Guerra SM, Cañibano C, Martín JF, Aparicio JF (2011b) Functional conservation of PASLuxR transcriptional regulators in polyene macrolide biosynthesis. Metab Eng 13:756-767. doi:10.1016/j.ymben.2011.09.011

Santos-Aberturas J, Vicente CM, Payero TD, Martín-Sánchez L, Cañibano C, Martín JF, Aparicio JF (2012) Hierarchical control on polyene macrolide biosynthesis: PimR modulates pimaricin production via the PAS-LuxR transcriptional activator PimM. PLoS One 7, e38536. doi:10.1371/journal.pone.0038536

Santos-Aberturas J, Engel J, Dickerhoff J, Dörr M, Rudroff F, Weisz K, Bornscheuer UT (2015) Exploration of the substrate promiscuity of biosynthetic tailoring enzymes as a new source of structural diversity for polyene macrolide antifungals. ChemCatChem 7:490-500. doi:10.1002/cctc. 201402773

Seco EM, Pérez-Zúñiga FJ, Rolón MS, Malpartida F (2004) Starter unit choice determines the production of two tetraene macrolides, rimocidin and CE-108, in Streptomyces diastaticus var. 108. Chem Biol 11:357-366. doi:10.1016/j.chembiol.2004.02.017

Seco EM, Fotso S, Laatsch H, Malpartida F (2005) A tailoring activity is responsible for generating polyene amide derivatives in Streptomyces diastaticus var. 108. Chem Biol 12:1093-1101. doi: 10.1016/j.chembiol.2005.08.007
Seco EM, Miranzo D, Nieto C, Malpartida F (2010) The pcsA gene from Streptomyces diastaticus var. 108 encodes a polyene carboxamide synthase with broad substrate specificity for polyene amides biosynthesis. Appl Microbiol Biotechnol 85:1797-1807. doi:10.1007/ s00253-009-2193-3

Shibata T, Tsuji S, Ito Y, Udagawa S, Suzuki M, Narita A, Kazama A, Asai Y, Sato T, Sagara K, Honda T, Hiraki R, Iwaida M, Okamoto K, Mochizuki E, Suganuma O (1991) Comparison of natamycin and sorbate residue levels and antifungal activities on the surfacetreatment of gouda-type cheese. J Food Hygienic Soc Japan 32: $389-401$

Siricururatana P, Iyer MM, Manns DC, Churey JJ, Worobo RW, PadillaZakour OI (2013) Shelf-life evaluation of natural antimicrobials for Concord and Niagara grape juices. J Food Prot 76:72-78. doi:10. 4315/0362-028X.JFP-12-144

Sletta H, Borgos SE, Bruheim P, Sekurova ON, Grasdalen H, Aune R, Ellingsen TE, Zotchev SB (2005) Nystatin biosynthesis and transport: $n y s H$ and $n y s G$ genes encoding a putative $\mathrm{ABC}$ transporter system in Streptomyces noursei ATCC 11455 are required for efficient conversion of 10-deoxynystatin to nystatin. Antimicrob Agents Chemother 49:4576-4583. doi:10.1128/AAC.49.11.45764583.2005

Stack JA, Harrison M, Perrett LL (2002) Evaluation of a selective medium for Brucella isolation using natamycin. J Appl Microbiol 92: 724-728. doi:10.1046/j.1365-2672.2002.01595.x

Stark J (2003) Natamycin: an effective fungicide for food and beverages. Natural antimicrobials for the minimal processing of foods. CRC Press, Boca Raton, In, pp 82-95

Struyk AP, Hoette I, Drost G, Waisvisz JM, van Eek T, Hoogerheide JC (1957-1958) Pimaricin, a new antifungal antibiotic. Antibiot Annu 5:878-885

Su J, Wang YC, Zhang SK, Ren XB (2014) Antifungal agents against Aspergillus niger for rearing rice leaffolder larvae (Lepidoptera: Pyralidae) on artificial diet. J Econ Entomol 107:1092-1100. doi: 10.1603/EC13296

Suloff EC, Marcy JE, Hackney CR, Sumner SS, Bishop JR (2003) Comparative study of a semisynthetic derivative of natamycin and the parent antibiotic on the spoilage of shredded cheddar cheese. J Food Protect 66:1499-1502

Sunada A, Kimura K, Nishi I, Toyokawa M, Ueda A, Sakata T, Suzuki T, Inoue Y, Ohashi Y, Asari S, Iwatani Y (2014) In vitro evaluations of topical agents to treat Acanthamoeba keratitis. Ophthalmology 121: 2059-2065. doi:10.1016/j.ophtha.2014.04.013

Takeshita N, Higashitsuji Y, Konzack S, Fischer R (2008) Apical sterolrich membranes are essential for localizing cell end markers that determine growth directionality in the filamentous fungus Aspergillus nidulans. Mol Biol Cell 19:339-351. doi:10.1091/ mbc.E07-06-0523

Taylor BL, Zhulin IB (1999) PAS domains: internal sensors of oxygen, redox potential, and light. Microbiol Mol Biol Rev 63:479-506

te Welscher YM, ten Napel HH, Balagué MM, Souza CM, Riezman H, de Kruijff B, Breukink E (2008) Natamycin blocks fungal growth by binding specifically to ergosterol without permeabilizing the membrane. J Biol Chem 283:6393-6401. doi:10.1074/jbc.M707821200

te Welscher YM, Jones L, van Leeuwen MR, Dijksterhuis J, de Kruijff B, Eitzen G, Breukink E (2010) Natamycin inhibits vacuole fusion at the priming phase via a specific interaction with ergosterol. Antimicrob Agents Chemother 54:2618-2625. doi:10.1128/AAC. 01794-09

te Welscher YM, van Leeuwen MR, de Kruijff B, Dijksterhuis J, Breukink E (2012) Polyene antibiotic that inhibits membrane transport proteins. Proc Natl Acad Sci U S A 109:11156-11159. doi:10. 1073/pnas. 1203375109

Thomas PA (2003) Current perspectives on ophthalmic mycoses. Clin Microbiol Rev 16:730-797. doi:10.1128/CMR.16.4.730-797.2003 
Thomas PA, Kaliamurthy J (2013) Mycotic keratitis: epidemiology, diagnosis and management. Clin Microbiol Infect 19:210-220. doi: 10.1111/1469-0691.12126

van Leeuwen MR, Golovina EA, Dijksterhuis J (2009) The polyene antimycotics nystatin and filipin disrupt the plasma membrane, whereas natamycin inhibits endocytosis in germinating conidia of Penicillium discolor. J Appl Microbiol 106:1908-1918. doi:10. 1111/j.1365-2672.2009.04165.x

van Wezel GP, McDowall KJ (2011) The regulation of the secondary metabolism of Streptomyces: new links and experimental advances. Nat Prod Rep 28:1311-1333. doi:10.1039/c1np00003a

Vicente CM, Santos-Aberturas J, Guerra SM, Payero TD, Martín JF, Aparicio JF (2009) PimT, an amino acid exporter controls polyene production via secretion of the quorum sensing pimaricin-inducer PI-factor in Streptomyces natalensis. Microb Cell Fact 8:33. doi:10. $1186 / 1475-2859-8-33$

Vicente CM, Santos-Aberturas J, Payero TD, Barreales EG, de Pedro A, Aparicio JF (2014) PAS-LuxR transcriptional control of filipin biosynthesis in S. avermitilis. Appl Microbiol Biotechnol 98:93119324. doi:10.1007/s00253-014-5998-7

Vicente CM, Payero TD, Santos-Aberturas J, Barreales EG, de Pedro A, Aparicio JF (2015) Pathway-specific regulation revisited: crossregulation of multiple disparate gene clusters by PAS-LuxR transcriptional regulators. Appl Microbiol Biotechnol 99:5123-5135. doi:10.1007/s00253-015-6472-x

Volokhan O, Sletta H, Ellingsen TE, Zotchev SB (2006) Characterization of the P450 monooxygenase NysL, responsible for C-10 hydroxylation during biosynthesis of the polyene macrolide antibiotic nystatin in Streptomyces noursei. Appl Environ Microbiol 72:2514 2519. doi:10.1128/AEM.72.4.2514-2519.2006

Volpon L, Lancelin JM (2002) Solution NMR structure of five representative glycosylated polyene macrolide antibiotics with a steroldependent antifungal activity. Eur J Biochem 269:4533-4541. doi: 10.1046/j.1432-1033.2002.03147.x
Wachtler V, Balasubramanian MK (2006) Yeast lipid rafts? - an emerging view. Trends Cell Biol 16:1-4. doi:10.1016/j.tcb.2005.11.008

Wang D, Yuan J, Gu S, Shi Q (2013) Influence of fungal elicitors on biosynthesis of natamycin by Streptomyces natalensis HW-2. Appl Microbiol Biotechnol 97:5527-5534. doi:10.1007/s00253-0134786-0

Wang YY, Ran XX, Chen WB, Liu SP, Zhang XS, Guo YY, Jiang XH, Jiang H, Li YQ (2014a) Characterization of type II thioesterases involved in natamycin biosynthesis in Streptomyces chattanoogensis L10. FEBS Lett 588:3259-3264. doi:10.1016/j. febslet.2014.07.010

Wang S, Liu F, Hou Z, Zong G, Zhu X, Ling P (2014b) Enhancement of natamycin production on Streptomyces gilvosporeus by chromosomal integration of the Vitreoscilla hemoglobin gene $(\mathrm{vgb})$. World J Microbiol Biotechnol 30:1369-1376. doi:10.1007/s11274-0131561-4

Wei J, Meng X, Wang Q (2011) Enhanced production of aureofuscin by over-expression of AURJ3M, positive regulator of aureofuscin biosynthesis in Streptomyces aureofuscus. Lett Appl Microbiol 47: 506-513. doi:10.1111/j.1472-765X.2011.03003.x

Wu H, Liu W, Dong D, Li J, Zhang D, Lu C (2014) SlnM gene overexpression with different promoters on natamycin production in Streptomyces lydicus A02. J Ind Microbiol Biotechnol 41:163172. doi:10.1007/s10295-013-1370-7

Yu P, Liu SP, Bu QT, Zhou ZX, Zhu ZH, Huang FL, Li YQ (2014) WblAch, a pivotal activator of natamycin biosynthesis and morphological differentiation in Streptomyces chattanoogensis L10, is positively regulated by AdpAch. Appl Environ Microbiol 80:68796887. doi:10.1128/AEM.01849-14

Zhou ZX, Xu QQ, Bu QT, Liu SP, Yu P, Li YQ (2015) Transcriptomeguided identification of SprA as a pleiotropic regulator in Streptomyces chattanoogensis. Appl Microbiol Biotechnol 99: 1287-1298. doi:10.1007/s00253-014-6132-6 